\title{
EVALUATING THE
}

REAL EFFECT OF BANK BRANCHING DEREGULATION

COMPARING CONTIGUOUS COUNTIES ACROSS U.S. STATE BORDERS

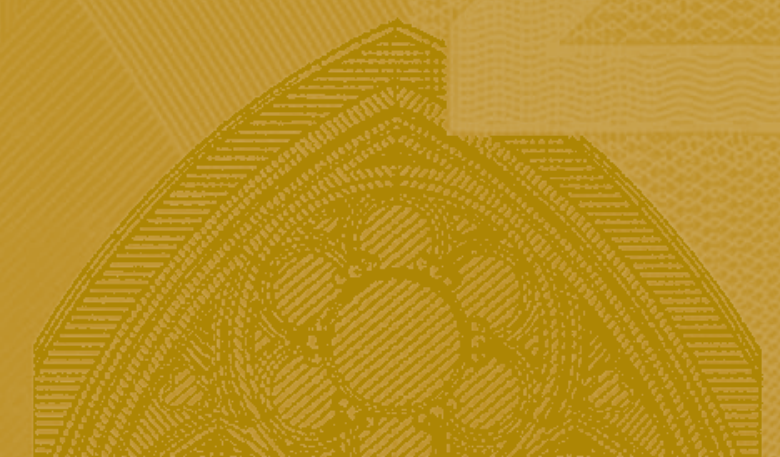

by Rocco R. Huang 


\section{WORKING PAPER SERIES}

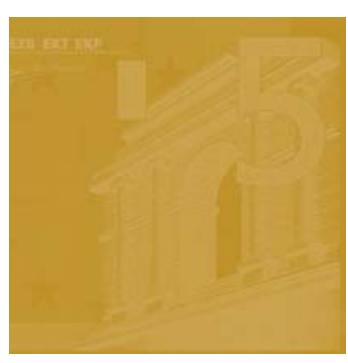

EVALUATING THE REAL EFFECT OF BANK BRANCHING DEREGULATION COMPARING CONTIGUOUS
COUNTIES ACROSS U.S. STATE
BORDERS

by Rocco R. Huang ${ }^{2}$
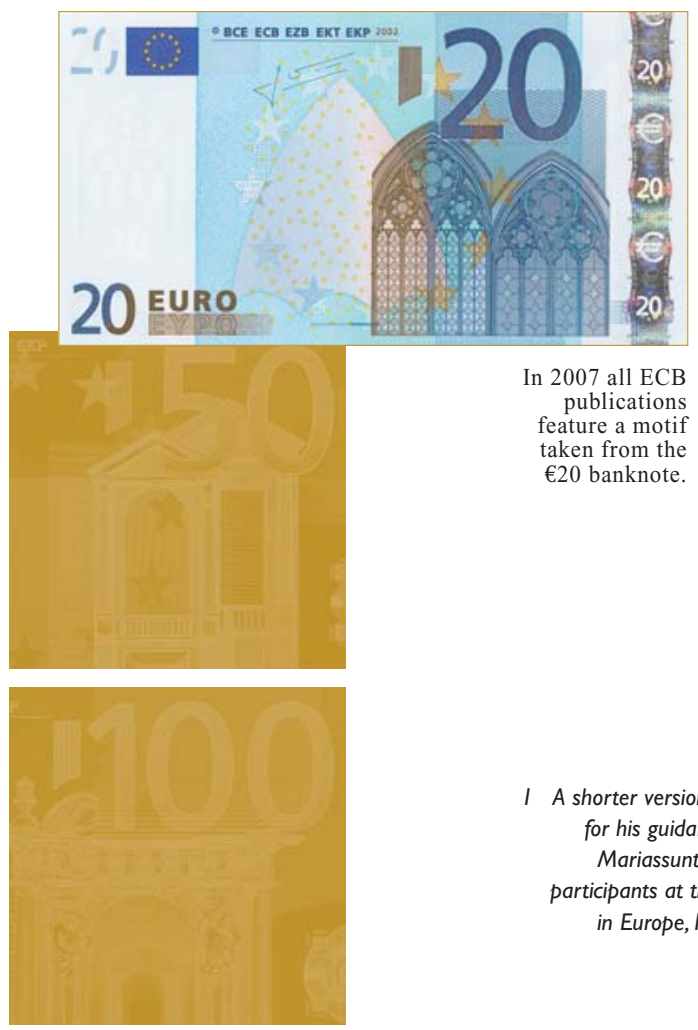


\section{Lamfalussy Fellowships}

This paper has been produced under the ECB Lamfalussy Fellowship programme. This programme was launched in 2003 in the context of the ECB-CFS Research Network on "Capital Markets and Financial Integration in Europe". It aims at stimulating high-quality research on the structure, integration and performance of the European financial system.

The Fellowship programme is named after Baron Alexandre Lamfalussy, the first President of the European Monetary Institute. Mr Lamfalussy is one of the leading central bankers of his time and one of the main supporters of a single capital market within the European Union.

Each year the programme sponsors five young scholars conducting a research project in the priority areas of the Network. The Lamfalussy Fellows and their projects are chosen by a selection committee composed of Eurosystem experts and academic scholars. Further information about the Network can be found at http://www.eu-financial-system.org and about the Fellowship programme under the menu point "fellowships".

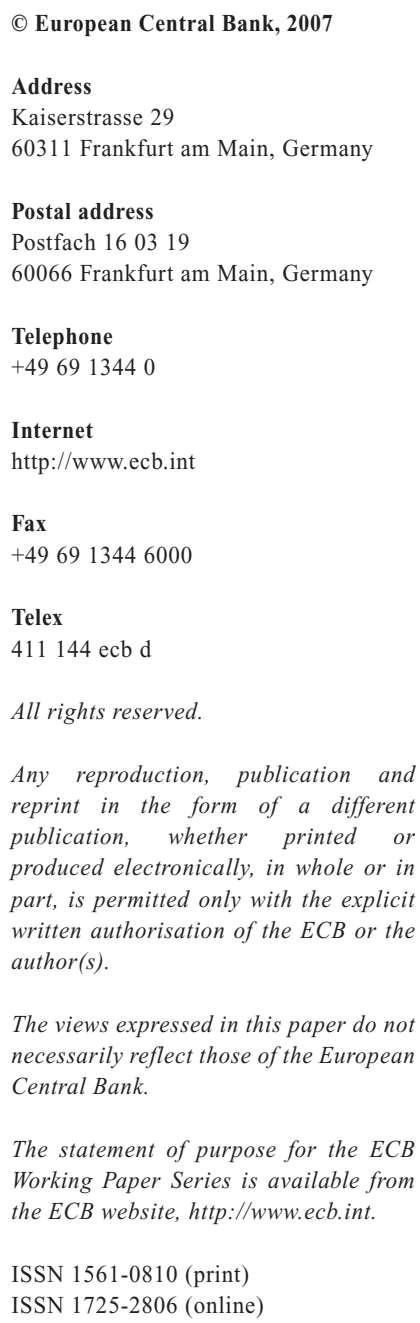

The views expressed in this paper do not necessarily reflect those of the European Central Bank. 


\section{CONTENTS}

Abstract 4

Non-technical summary 5

1 Introduction 7

2 Matching of contiguous counties across regulation change borders

2.1 Identifying contiguous counties

2.2 Contiguous counties are similar in observable characteristics $\quad \mid 7$

2.3 Hinterland counties 20

3 Methodology: estimating the treatment effects 22

3.1 Collapsing of information into "pre-" and "post-" period

3.2 Correcting bias in the point estimate of treatment effects (TE)

3.3 Establishing correct standard errors of the estimation procedure

3.4 Using the non-event sample to correct biases in the point estimate of actual treatment effects

4 Randomizing placebo deregulations on the non-event borders

4.1 Conducting simulations and obtaining estimates of "treatment effects"

4.2 Adjusting for the income gap and the growth opportunity gaps

4.3 Creating the statistical table of critical values for the treatment effect estimator

4.4 Taking into account spatial correlations of treatment effects

5 Evaluating twenty-three actual events of deregulations

5.1 Obtaining point estimates of treatment effects

5.2 Establishing statistical significance

6 Robustness check: geographic spillover of deregulation effects?

7 Discussions

8 Implications for european banking market integration

References

Appendix: Contiguous counties across regulation change borders

European Central Bank Working Paper Series 


\begin{abstract}
This paper proposes a new methodology to evaluate the economic effect of statespecific policy changes, using bank-branching deregulations in the U.S. as an example. The new method compares economic performance of contiguous counties on opposite sides of state borders, where on one side restrictions on statewide branching were removed relatively earlier, to create a natural "regression discontinuity" setup. The study uses a total of 285 pairs of contiguous counties along 38 segments of such regulation change borders to estimate treatment effects for 23 separate deregulation events. To distinguish real treatment effects from those created by data-snooping and spatial correlations, fictitious placebo deregulations are randomized (permutated) on another 32 segments of non-event borders to establish empirically a statistical table of critical values for the estimator. The method determines that statistically significant growth accelerations can be established at a > $90 \%$ confidence level in five out of the 23 deregulation events examined. "Hinterland counties" within the still-regulated states, but farther away from the state borders, are used as a second control group to consider and reject the possibility that cross-border spillover of deregulation effects may invalidate the empirical design.
\end{abstract}

JEL Classification: G21; G28; O43

Keywords: Banking deregulation; Economic growth; Regression discontinuity 


\section{Non-technical summary}

This paper designs a new methodology to evaluate the effects of policy changes that are specific to sub-national regions. The main idea is to compare two neighboring geographic units that are separated by a political border, but are otherwise very similar, to exploit the policy differences that sometimes arise across the border because of some deregulations or reforms that take place early in only one of the two regions.

If a policy reform takes place in Michigan, and subsequently Michigan grows faster than the national average; we are tempted to conclude that the reform has produced positive effects. But this may not be a good comparison: When you compare Michigan to Texas, it is quite easy for you to find large growth rate differences, either positive or negative, simply because the two state economies always move in opposite directions. But you can not immediately interpret this as the effect of policy changes in Michigan.

This paper's solution is to compare the border areas of two neighboring U.S. states where policies differ across the state border. In these areas, income level, economic structure, etc, are very similar. And more importantly, access to transport, climate, agglomeration economy, etc are similar too. These factors are usually very difficult for econometricians to explicitly control for; but between two neighboring areas these differences are arguably very small. Therefore, the effect of a certain policy change should be more precisely identified by comparing the differential outcomes across the border.

In this paper, I use the deregulation of bank geographic expansion in the United States as an example to illustrate the application of this methodology. U.S. banking market used to be very fragmented. Until the late $1970 \mathrm{~s}$, regulations used to restrict a bank from setting up branches outside its home county. But in the next two decades, in a piecemeal fashion, individual states one after another removed the anti-competition restrictions, and these deregulations were supposed to introduce more competition in the banking markets and potentially generate faster economic growth.

One way to verify whether this claim is true or not is to compare the economic performance of two neighboring US counties separated by a state border, when bank expansion restrictions were already removed on one side of the border but not yet on the other side. This study identifies 38 segments of such "regulation change borders," and along them 279 pairs of neighboring counties, and thus creates a regression discontinuity setting, in which two very similar counties are assigned different treatments simply because they are cut off by a political border. If indeed a certain deregulation has positive effects, then we should see that in the border areas, a county in the deregulating states grows faster than its neighbor on the other side of the border right after the deregulation event.

Using this methodology, this study finds that the state-level deregulations in the US produced uneven results: large effects for some states, insignificant for many others, and negative for the rest. The study shows that the bank branching deregulations that took place before 1985 were in general not followed by faster economic growth. As a matter of fact, these earlier liberalizers grew on average $0.12 \%$ per year slower compared to their neighbors. However, it does not follow that our results have to be inconsistent with the Jayaratne and Strahan (1996) study, which finds positive effects on average. We need to look into the heterogeneity of the results to make a fair and comprehensive assessment. 
In contrast to the negative results of the earlier deregulation events, deregulations taking place after 1985 were in general associated with positive effects and there were five cases (Louisiana, Michigan, Missouri, Oklahoma, and Tennessee) in which the intrastate branching deregulations were followed by statistically significant growth accelerations. In all of these five cases, inter-state banking deregulations took place before or at least at the same year of the intra-state branching deregulations, and the introduction of nationwide potential competitors naturally created stronger effects than did most of the statewide branching deregulations in the first half of 1980s that typically open the markets to only in-state or regional competitors.

The US experiences have implications for European banking market integration because we can draw comparisons between US states and European countries, and the US counties and the regions within a European country. The results of this study would suggest that removing barriers that fragment the national banking market within a European country can produce greater benefit for the national economy if foreign investors and banks do not have any barrier to own and control domestic banks.

Furthermore, this study finds that the removal of statewide branching restrictions had uneven effects on different states, depending on the actual level of competition already existing in the local markets before the removal of legal barriers. From the results it is noticed that in previously more concentrated (competitive) local markets, deregulations were in general associated with larger (smaller) effects. A similar difference is found in the comparison of rural versus urban banking markets. The reason is quite straightforward: if a local market is already quite competitive although the competition arises only from the locals; then the exclusion of competition from outside the county is unlikely to be a binding constraint for the local economy and borrowers, and the removal of the barriers is unlikely to create much extra benefit either. This is true for most urban markets (such as New York and Los Angles) in the US, because in these places local competitors are already sufficient for the market to be very contestable.

In Europe, domestic banking markets are more competitive in some countries (regions) than in others, and the introduction of domestic or Europe-wide competition could generate uneven benefits across countries and regions. In Germany and Italy for example, domestic markets are fragmented for historical and institutional reasons. In such markets, the introduction of outside competition could contribute significantly to competition. In contrast, such extra benefits could be smaller for metropolitan areas such as London or Paris, because the local players alone have already created fierce competition among themselves.

Furthermore, this study finds that the deregulations taking place in the later half of the sample generated greater economic benefit than did the earlier deregulations. This is consistent with DeLong and DeYoung (2007)'s results that there exists so-called "learning-by-observing" in the banking sector consolidation process so that the earlier M\&As were typically less successful than the later ones. European banks, if they can learn by observing the US experiences, could more efficiently exploit the new competitive environment enabled by the removal of within-Europe barriers. Therefore, it is possible that a level playing field in Europe could create faster, greater, and wider benefits for the European economy. 


\section{Introduction}

Liberalization of the banking sector is, in general, shown to have had a positive impact on local economic growth (Levine [2004] provides a review of the related literature). In the United States, intrastate branching regulations imposed by state legislatures used to restrict a bank from making statewide branching expansions, and a bank holding company from folding its subsidiaries in different counties into a single operation entity. Beginning in the mid-1970s, individual states lifted these restrictions at different times in a piecemeal fashion. The staggered nature of the deregulation timings has been exploited by researchers to study the effects of banking deregulation on the local economy, because the restriction on interstate branching (removed only much later) had essentially produced 50 segregated banking systems within the United States, one for each state. ${ }^{3}$

Potentially, removal of restrictions on bank entry and expansion could facilitate mergers and acquisitions, promote competition, increase bank efficiency, and thus, could help local economic growth. For example, Jayaratne and Strahan (1997) find that the relaxing of restrictions on bank expansion led to greater efficiency of banks, although they find no increase of credit supply. Using state-level data, Jayaratne and Strahan (1996) provide well-cited evidence that the deregulations were in general associated with faster local economic growth. Strahan (2003) provides a good review of the available evidence in favor of the positive effects of the deregulations.

However, we believe that it remains an open empirical question whether

\footnotetext{
${ }^{3}$ For a long period of time in the United States, an otherwise unified nation, banks from other states were viewed as "foreign". Interstate banking regulations used to strictly forbid out-of-state banks from acquiring a state's incumbent banks, let alone opening new in-state branches. Until 1994, even if a state amended its law and started to allow interstate banking, newly acquired banking assets could not be folded into the acquirer's banking operations outside the state.
} 
regulation of commercial banks' expansion was a binding constraint on the growth of the local economy, and whether removal of this restriction had created immediate and significant economic benefits for the local economy. Studies in existing literature tend to find a significant positive effect from the deregulation of branching on the local economy, but most of them use a state as the unit of analysis. This practice we argue is open to a number of econometric problems. Individual states deregulated branching in waves; in very few cases (which are the subject of our study) did states in the same region deregulate at very different times. To increase the degree of freedom in regressions, previous studies typically have had to use very diverse states from different regions to form the treatment and the control group; they were forced, for example, to compare Texas with Michigan, although the two states are not synchronized in their business cycles. After controlling for regional effects, Freeman (2002) and Wall (2004) find that the positive effect of banking deregulation on the real economy is not an unambiguous result; in some regions they are positive, whereas in many more others, they are actually negative. Furthermore, banking deregulation could be induced by an expectation of future growth opportunities (unobservable to econometricians), which could create a spurious correlation between banking deregulation and future growth accelerations. Therefore, it is possible that the episodes of growth accelerations identified by previous studies could be the manifestation of heterogeneity of growth paths in different regions (Garrett et al., 2004), or difference of expected future growth opportunities across states, independent of, or not caused by, changes in state-level banking regulations.

This study uses a novel procedure to establish whether a branching deregulation event produces a significantly positive treatment effect or not. The new method compares 
economic performance of contiguous counties separated only by state borders in cases in which one state deregulated intrastate branching earlier than did the other. Because these counties are immediately adjacent neighbors, they are expected to be similar in both observable, and more importantly, unobservable conditions, and will tend to follow similar growth paths in the absence of regulation or policy changes. This study is not the first to use this geographic-matching methodology to conduct policy evaluations, ${ }^{4}$ but it adopts an even more precise method, in that it carefully matches and compares each "treated" county with only its own paired neighbor across the border, instead of roughly comparing two strips of land on opposite sides of a long border.

Using a county as a unit of analysis can minimize endogeneity problems. Kroszner and Strahan (1999) find that the relative strength of winners (large banks and small, bank-dependent firms) and losers (small banks and the rival insurance firms) in bank deregulation can explain the timing of branching deregulation across states. In this study, however, it is unlikely that economic conditions and the financial sector structure in a county can influence regulatory decisions made by the state legislature, which has to accommodate the interests of all constituencies, not only a small group of border counties. Furthermore, the lack of commuting labor movement across most state borders (according to the "Journal to Work" census) ensures that a regulatory shock that affects the local economy should translate into perceivable short-term changes in local incomes

\footnotetext{
${ }^{4}$ Fox (1986) finds that sales tax differences between neighboring states affect retail sales in border counties. Card and Kruger (1994) look at the New Jersey-Pennsylvania border area to examine the effects of an increase in the minimum wage. Black (1999) examines the price of houses located on school-district boundaries and finds that parents are willing to pay $2.5 \%$ more for a $5 \%$ increase in test scores. Using a similar methodology, Holmes (1998) finds that as a group, counties on the pro-business side of state borders experience faster manufacturing growth.
} 
observable to econometricians. ${ }^{5}$ Note that New York - New Jersey border is not included in our sample.

Using state-level intrastate branching deregulation events as quasi-experiments, this study focuses on how removals of restrictions on statewide branching affect growth by comparing growth rate of per capita income on opposite sides of regulation change borders, after adjusting for income gap and growth opportunity gap that could potentially bias the point estimate of treatment effects. Fictitious placebo deregulations are randomized on out-of-sample non-event borders where such dramatic cross-border regulatory difference as that seen in regulation change borders did not exist, to empirically obtain a statistical table of critical values, which helps us to statistically distinguish real treatment effects from the results of potential data-snooping. The same method also helps adjust the critical values for spatial correlations of treatment effects within a chain of neighboring county-pairs (which could bias the standard errors downward).

Among the 23 events of deregulations taking place during a 15-year period from 1975 to 1990 , this study finds statistically significant growth accelerations after deregulation in only five of them, and none of these events took place prior to 1985 . The new results call for further research on why regulation and deregulation of commercial banks' geographic expansions did not seem to substantially affect the local economy. We provide several plausible explanations.

\footnotetext{
${ }^{5}$ This divide, however, does not make the contiguous county economies on opposite sides of state borders isolated from each other in the long run. In responding to branching regulations that had been in place since the Great Depression, no frictions were great enough to hold off necessary economic adjustment for such a long period of time. By the time a deregulation event took place in the 1980s, the two contiguous counties were more likely to be in an equilibrium state already, with respect to observable and unobservable local factors, including the then prevailing banking regulation arrangements. In the wake of a deregulation shock, however, adjustment taking place in the newly deregulated county (presumably toward a higher income level than its neighbor if deregulation should have positive effects) and cross-border growth rate difference created by this unilateral adjustment, should be perceivable in the short term (e.g., five years) as the pair slowly finds its way to a new equilibrium.
} 
The economic impacts of regulation or deregulation of U.S. commercial banks could well be overstated. Kane (1996) and Kroszner and Strahan (1999) have pointed out the irony that the cost of regulation is usually the lowest by the time it is removed. In the history of the U.S. financial service industry, most of the effects targeted by the rescission will have already been tolerated by the enforcement system for years before an exclusionary statute comes to be formally rescinded, and more importantly, will have been from the beginning constantly subject to erosions by market players through legal loopholes, contractual and information processing innovations, regulatory/structural arbitrage $^{6}$, and interpretive changes in statute-implementing regulations that regulatory bodies actually enforce. As Kane (1981, p. 359) asserts, "In the 1970s, loophole mining and fabrication became the main business of modern depository institutions."

Also, the U.S. economy is much less dependent on banks than are continental European economies, and thus, burdensome regulations imposed on banks could have but limited real effects. Bank lending may not be critical, because other sources of financing can easily replace lending by commercial banks (Marquis, 2001). There is already empirical evidence suggesting that bank loans have no significant impact on economic outputs. ${ }^{7}$ Considering the important role already played by nonbank financial institutions (which have not been geographically restricted) and capital markets already played vis-àvis commercial banks before the deregulation, it is not clear whether commercial banks

\footnotetext{
${ }^{6}$ US Banking Act of 1971 defines a bank as an institution that offeres demand deposits and originate commercial and industrial loans. A money market mutual fund is not a bank because it does not originate loans, and a finance company is not a bank because it does not accept demand deposits.

${ }^{7}$ Driscoll (2004) uses a panel of state-level data to find that bank loans have small, often negative and statistically insignificant, effects on output. Ashcraft (2006) estimates that the elasticity of real state income to bank loan supply is close to zero and is definitely no larger than $10 \%$. Ashcraft and Campello (2003) show that bank lending is demand-driven and influenced by local economic conditions.
} 
provided any credit service to the economy that could not be replaced by nonbank financial institutions. ${ }^{8}$ Furthermore, post-deregulation consolidations of banks could negatively impact smaller and newer firms that are the most dependent on banks. ${ }^{9}$

Below we provide a roadmap for the rest of the paper. Section 2 introduces the procedure of identifying regulation change borders and contiguous counties. In Section 3, the empirical strategies are introduced. There are several econometric difficulties that need to be addressed: First, how should the difference-in-differences treatment effect be defined to avoid potentially understating standard errors? Second, how can we correct biases in the point estimate of treatment effects? Third, how can we establish correct standard errors, and thus, statistical significance of the estimates, through randomizationtype fictitious "placebo deregulation events"? In Sections 4, 5, and 6, the proposed strategy is implemented. In Section 4, a statistical table of critical values is empirically created through a randomization procedure, also taking into account the influence of spatial dependences. In Section 5, the economic effects of each of the 23 events of branching deregulations are assessed, based on the critical values. In Section 6, using hinterland counties as a second control group, we consider and reject the possibility of cross-border spillover of deregulation effects influencing the results. Finally, in Section 7

\footnotetext{
${ }^{8}$ According to Berger, Kashyap, and Scalise (1995), only $20 \%$ of nonfarm and nonfinancial corporate debts were provided by these commercial banks in 1980; this ratio continued to drop through the 1980s. Finance companies, in contrast, facing few geographic expansion restrictions, provided nearly $10 \%$ of loans to nonfarm and nonfinancial firms. Many finance companies specialize in the factoring of trade account receivables, equipment loans, or leases, which are particularly relevant to small businesses that traditionally depend on banks. More importantly, a large number of entrepreneurs finance their ventures by taking second mortgages on their houses or using the generous limits on their personal credit cards or home equity lines of credit. None of these nonbank credit institutions (or products) is geographically restricted by the branching regulations.

${ }^{9}$ Berger et al. (2005) provide evidence consistent with the belief that small banks are better able to collect and act on soft information than large banks are. In particular, large banks are less willing than small banks to lend to those whose credit is "difficult" from the information standpoint, such as firms with no financial records. Brickley, Linck, and Smith (2003) also supply evidence that small, locally owned banks have a comparative advantage over large banks within specific environments.
} 
we discuss several plausible explanations about why regulation and deregulation of commercial banks' geographic expansions, in most cases, appeared not to have substantially affected the local economy. In Section 8, we discuss the implications of our results for European banking market integration.

\section{Matching of Contiguous Counties across Regulation Change Borders}

To assess the real effects of deregulations by comparing the economic performance of the treatment group vs. the control group, one first needs to look for pairs of neighboring states separated by the so-called regulation change borders. To be included in the study, we require that, for a pair of states, and thus their bilateral border, bank branching expansions in the second state must remain restricted for at least three years after restriction in the first state was removed. These borders are called regulation change borders. In the research sample we eventually composed, the average gap between the two states' deregulation timings reaches nearly six years, which we believe is sufficiently long for the economic effects of regulatory differences across state borders to be observed, if they exist at all.

\subsection{Identifying contiguous Counties}

Thirty-eight segments of such regulation change borders meeting the above requirements are identified. Borders of Western states (i.e., Montana, Wyoming, Colorado, New Mexico, and all states to the west of them) are excluded from the sample ${ }^{10}$. These regulation change borders are listed in Table 1 and highlighted in the map in

\footnotetext{
${ }^{10}$ It is much more difficult to identify good match of contiguous counties in the western states. In the eastern states, border counties on opposite sides of state borders are typically of fairly uniform width, nicely trace out the regulation change borders, forming strips of land on opposite sides of borders. In contrast, border counties in the western states are much larger in size, irregular in shape and less densely
} 
Figure 1. Using these borders, 23 events of state-level branching deregulations throughout the United States spanning from the 1970s to the 1980s can be evaluated, regarding their impacts on the local economy. These deregulation events include (in chronological order): Maine (75), New York (76), New Jersey (77), Virginia (78), Ohio (79), Connecticut (80), Alabama (81), Pennsylvania (82), Georgia (83), Massachusetts (84), Nebraska (85), Tennessee (85), Mississippi (86), Kansas (87), Michigan (87), North Dakota (87), West Virginia (87), Illinois (88), Louisiana (88), Oklahoma (88), Texas (88), Missouri (90), and Wisconsin (90).

populated. This exclusion requirement does not reduce the sample size significantly, becaue most of the western states deregulated bank branching much earlier than the rest of the U.S., and thus, there are few cross-border regulatory differences in the west for us to exploit. 
Figure 1: "Regulation change borders"

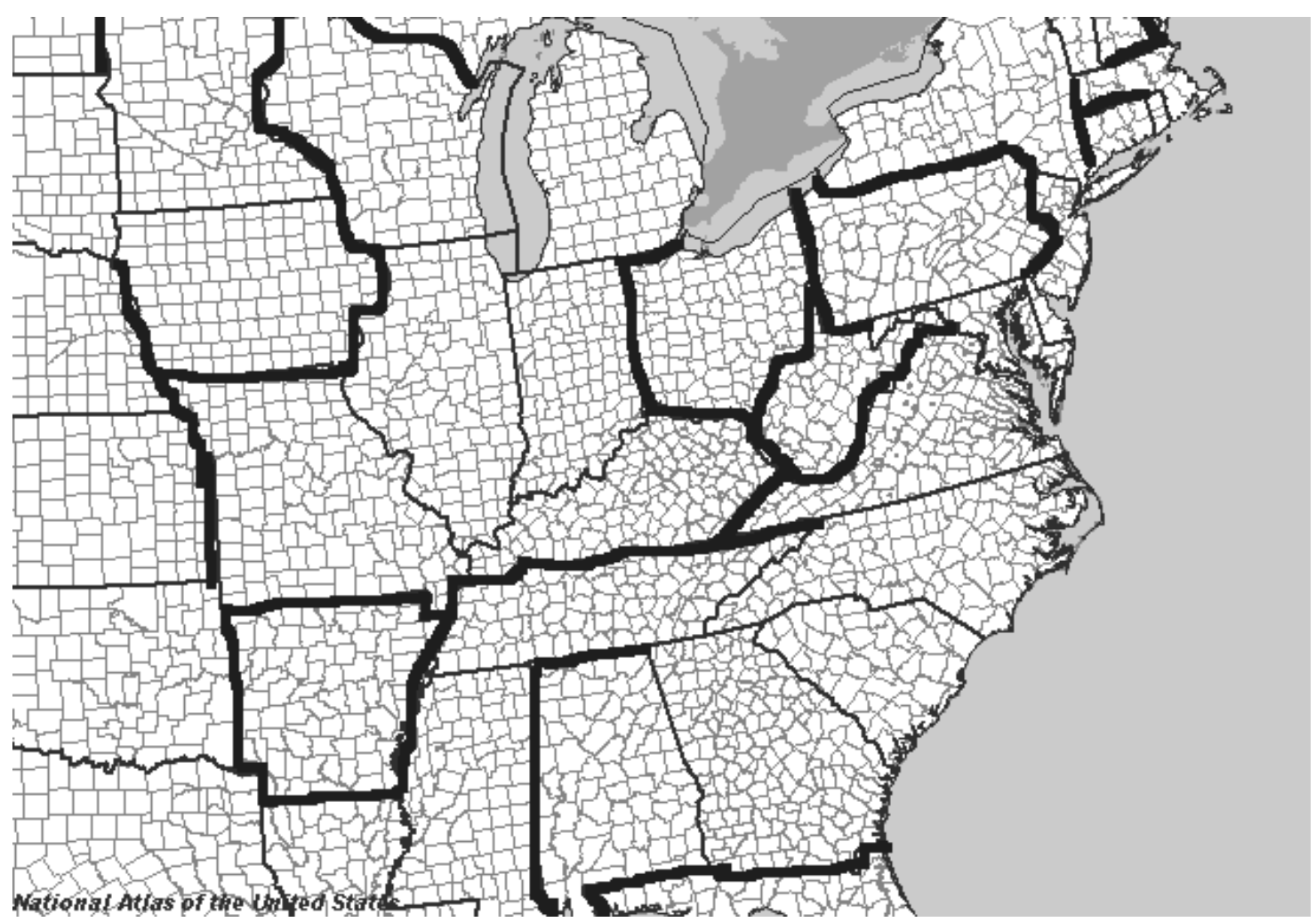

Note: This study identifies 38 segments of so-called regulation change borders, which are highlighted in the map. For at least three years, and on average six years, there were regulatory differences across these regulation change borders: banks on side of the borders were relieved from restriction on statewide branching; while on the other side, restrictions were eventually removed but at least three years later. See Section 2.1 for details. 
Table 1: Paired states and regulation change borders

\begin{tabular}{ll|ll}
\hline Early Deregulator & & & Late Deregulator \\
\hline Maine & 1975 & 1987 & New Hampshire \\
New York & 1976 & 1980 & Connecticut \\
New York & 1976 & 1982 & Pennsylvania \\
New York & 1976 & 1984 & Massachusetts \\
New Jersey & 1977 & 1982 & Pennsylvania \\
Virginia & 1978 & 1985 & Tennessee \\
Virginia & 1978 & 1987 & West Virginia \\
Virginia & 1978 & 1990 & Kentucky \\
\hline Ohio & 1979 & 1982 & Pennsylvania \\
Ohio & 1979 & 1987 & Michigan \\
Ohio & 1979 & 1987 & West Virginia \\
Ohio & 1979 & 1989 & Indiana \\
Ohio & 1979 & 1990 & Kentucky \\
Connecticut & 1980 & 1984 & Massachusetts \\
\hline Alabama & 1981 & 1985 & Tennessee \\
Alabama & 1981 & 1986 & Mississippi \\
Alabama & 1981 & 1988 & Florida \\
\hline Pennsylvania & 1982 & 1987 & West Virginia \\
\hline Georgia & 1983 & 1988 & Florida \\
\hline Massachusetts & 1984 & 1987 & New Hampshire \\
\hline Nebraska & 1985 & 1990 & Missouri \\
Nebraska & 1985 & 1994 & Iowa \\
\hline Tennessee & 1985 & 1990 & Kentucky \\
Tennessee & 1985 & 1990 & Missouri \\
Tennessee & 1985 & 1994 & Arkansas \\
Mississippi & 1986 & 1994 & Arkansas \\
\hline Kansas & 1987 & 1990 & Missouri \\
\hline Michigan & 1987 & 1990 & Wisconsin \\
North Dakota & 1987 & 1993 & Minnesota \\
\hline West Virginia & 1987 & 1990 & Kentucky \\
\hline Illinois & 1988 & 1994 & Iowa \\
\hline Louisiana & 1988 & 1994 & Arkansas \\
\hline Oklahoma & 1988 & 1994 & Arkansas \\
\hline Texas & 1988 & 1994 & Arkansas \\
Missouri & 1990 & 1994 & Arkansas \\
Missouri & 1990 & 1994 & Iowa \\
Wisconsin & 1990 & 1993 & Minnesota \\
Wisconsin & 1990 & 1994 & Iowa \\
\hline & & & \\
\hline & & & \\
\hline
\end{tabular}

Note: Pairs of states that bilaterally form the 38 segments of regulation change borders are listed in the table, sorted by the year when the first state in each pair removed restrictions on statewide branching. The year when each state removed restrictions on statewide branching is also indicated in the table (original source: Amel, 1993). 
One then needs to match pairs of contiguous counties across these so-called regulation change borders. The National Atlas of the United States (http://www.nationalatlas.gov/) was used to identify 285 pairs of contiguous counties. The list of the county-pairs is available from the author upon request. In the study, the counties located in states that deregulated earlier than their neighbors will form the treatment group, while those located in states where restrictions were removed at least three years later will form the control group. About one third of the sample counties are located in metropolitan areas.

It has been a convention in the literature to use a county as the unit of local banking market (e.g., Berger, Demsetz, \& Strahan, 1999; Black \& Strahan, 2002; Prager \& Hannan, 1998; and Rhoades, 2000). Many researchers have used a county as the unit of the local economy to study the effect of bank activities on economic outputs ${ }^{11}$ (e.g., Ashcraft, 2005; Calomiris \& Mason, 2003; Clair et al., 1994; and Gilbert \& Kochin, 1989). In the Federal Reserve's definition of local banking markets (DiSalvo, 1999), which takes into account commuting patterns as well as other factors, a rural county is typically also a local banking market.

\subsection{Contiguous counties are similar in observable characteristics}

The geographic matching produces higher homogeneity between the treatment and control groups, and can potentially reduce background noises and standard errors when we estimate treatment effects, and thus, can increase the power of the tests. Contiguous counties are arguably similar in many unobservable factors, but it is difficult for econometricians to formally verify it (otherwise, they are observable in the first place). Nevertheless, here we can still analyze some observable characteristics.

\footnotetext{
${ }^{11}$ because Forni and Reichlin (1997) show that, in the United States, county-specific components of output fluctuations are 1.35 times greater than state-specific components.
} 
To give readers a better understanding of how geographic matching has improved from previous studies in identifying the control group at least in observable characteristics, we conduct a counterfactual experiment: In the year before deregulation, we calculate each deregulated (treated) county's average absolute difference (in terms of income per capita and manufacturing income share, respectively) from all counties nationwide that deregulated at least three years later. This alternative way of forming the control group is equivalent to the practices of Jayarante and Strahan (1996) and other typical studies in the literature, which obtain point estimate of treatment effect by comparing at certain points in time deregulated states with all other states nationwide that had yet to deregulate. For a specific deregulation event, the numbers tell us if counties in the control group are drawn nationwide from states that deregulated at least three years later, what the average absolute difference will be between the treatment group and control group counties, in terms of income per capita and manufacturing share, respectively.

In Table 2, the average differences between treatment and control group, achieved through the two different approaches of control-group sampling are compared based on income per capita and manufacturing income share, respectively, and reported by individual deregulation event. It is clear that in most deregulation events, geographic matching has produced a much smaller absolute difference between treatment and control groups, in these two observed characteristics, than what can be achieved in pooled regressions a la Jayarante and Strahan (1996). 
Table 2: How does the use of contiguous counties help reduce observable differences between treatment and control groups?

\begin{tabular}{|c|c|c|c|c|}
\hline & \multicolumn{2}{|c|}{$\begin{array}{c}\text { Absolute log difference }(\%) \\
\text { in income per capita }\end{array}$} & \multicolumn{2}{|c|}{$\begin{array}{c}\text { Absolute difference in } \\
\text { manufacturing income ratio }\end{array}$} \\
\hline & \multicolumn{4}{|c|}{ between treated counties and ... } \\
\hline & $\begin{array}{c}\text { Contiguous } \\
\text { border } \\
\text { counties }\end{array}$ & $\begin{array}{c}\text { Regulated } \\
\text { counties } \\
\text { nationwide }\end{array}$ & $\begin{array}{c}\text { Contiguous } \\
\text { border } \\
\text { counties }\end{array}$ & $\begin{array}{c}\text { Regulated } \\
\text { counties } \\
\text { nationwide }\end{array}$ \\
\hline Alabama & 15.33 & 23.70 & 0.17 & 0.21 \\
\hline Connecticut & 15.66 & 35.24 & 0.07 & 0.20 \\
\hline Georgia & 16.23 & 24.26 & 0.22 & 0.20 \\
\hline Illinois & 8.36 & 18.56 & 0.18 & 0.16 \\
\hline Kansas & 12.91 & 21.56 & 0.07 & 0.14 \\
\hline Louisiana & 16.32 & 24.86 & 0.14 & 0.15 \\
\hline Maine & 10.56 & 19.01 & 0.15 & 0.20 \\
\hline Massachusetts & 7.86 & 37.86 & 0.08 & 0.21 \\
\hline Michigan & 10.54 & 18.36 & 0.11 & 0.14 \\
\hline Mississippi & 11.73 & 35.20 & 0.08 & 0.14 \\
\hline Missouri & 13.07 & 25.86 & 0.17 & 0.16 \\
\hline Nebraska & 12.11 & 21.65 & 0.08 & 0.15 \\
\hline New Jersey & 6.36 & 31.18 & 0.10 & 0.19 \\
\hline New York & 12.28 & 22.90 & 0.14 & 0.20 \\
\hline North Dakota & 11.76 & 24.58 & 0.12 & 0.14 \\
\hline Ohio & 12.18 & 21.26 & 0.15 & 0.21 \\
\hline Oklahoma & 21.13 & 28.15 & 0.16 & 0.16 \\
\hline Pennsylvania & 6.61 & 18.64 & 0.19 & 0.18 \\
\hline Tennessee & 14.16 & 26.38 & 0.14 & 0.21 \\
\hline Texas & 14.89 & 14.35 & 0.31 & 0.12 \\
\hline Virginia & 19.20 & 22.29 & 0.14 & 0.19 \\
\hline West Virginia & 14.71 & 23.47 & 0.08 & 0.15 \\
\hline Wisconsin & 10.28 & 15.88 & 0.12 & 0.13 \\
\hline Total & 13.45 & 23.44 & 0.14 & 0.18 \\
\hline
\end{tabular}

Note: To give readers a sense of how geographic matching has improved on previous studies in identifying a better matched control group at least in some observable characteristics, we conduct a counterfactual experiment. For each deregulated (treated) county, at the time of deregulation, we also calculate its average differences (in terms of income per capita and manufacturing income ratio, respectively) from all counties nationwide that deregulated at least three years later. This alternative way of forming the control group is equivalent to the practice of Jayarante and Strahan (1996) and other typical studies in the literature, which produce point estimate of treatment effects by comparing at certain points in time deregulated states with all other states nationwide that had yet to deregulate. The numbers can tell us, for a specific treatment county, if its controls are drawn nationwide from states that deregulated at least three years later, as opposed to from contiguous counties, what will be the average differences between treatment group and control group counties, in terms of the two observable characteristics. In the Table, averaged by deregulation event, we present and compare the observed absolute differences between treatment and control group, achieved through the two different approaches of control-group sampling. It is clear that in almost all cases, geographic matching produces smaller absolute difference between treatment and control groups than what can be achieved in pooled regressions $a$ la Jayarante and Strahan (1996). See Section 2.2 for details. 
Certainly, if we scan the whole national sample, consider also counties that are not necessarily contiguous to the treatment counties, and retain only the best matched counties in these two observable characteristics (per capita income and manufacturing income share); we could form an even better matched control group. The reason for not doing so is that observable differences can be easily controlled for, do not pose a large challenge to econometricians, and thus, is not a major problem in this study. On the contrary, unobservable characteristics, in which contiguous counties are less likely to differ from each other, are what usually trouble econometricians because there is no way econometricians can explicitly adjust for unobservable growth opportunities, otherwise they are observable in the first place. Furthermore, there are many factors that are observable but difficult to exhaust, quantify, or control for, e.g., climate, access to transport, and agglomeration economy. However, these factors are less likely to differ or matter within a pair of contiguous counties. Therefore, the strategy adopted in the study, which takes into account such a tradeoff, is to use contiguous counties to minimize the difference in unobservable factors, and then explicitly adjust for the remaining observable differences, which is less difficult for econometricians.

\subsection{Hinterland counties}

A second control group of paired counties is also identified, which we name hinterland counties. They are located on the same side of the regulated counties, and therefore were also kept regulated longer than the deregulated counties on the opposite side of state borders. The hinterland counties, however, are farther away from the regulation change borders, and are not directly contiguous with the deregulated counties. Nevertheless, they remain contiguous to the border regulated counties on the same side of 
the border. In other words, hinterland counties are co-contiguous with the deregulated counties, with the border deregulated counties located in-between them. We identify 249 such hinterland counties. The list is available from the author upon request. For some deregulated counties, proper hinterland counties cannot be found for geographic reasons. ${ }^{12}$ In the study, the hinterland counties are used as a second control group to consider potential spillovers of deregulation effects across state borders, which could disqualify border counties as valid controls in the event of treatment. The rationale of this robustness check will be explained in detail in Section 6.

To help readers better understand the geographic terms we mention above, Figure 2 provides a graphical example: Georgia lifted the branching regulation in 1983, whereas Florida remained regulated until five years later in 1988. In this case, Brooks County in Georgia is a deregulated county; Madison County in Florida is a regulated county; and Taylor County farther within Florida is a hinterland county.

\footnotetext{
${ }^{12}$ There are several reasons why hinterland counties cannot be found for some county-pairs. One of the simple reasons is that the hinterland is the Gulf of Mexico. Another common reason is that the candidate hinterland county borders another state that had deregulated earlier, which creates a new source of spillover potential.
} 
Figure 2: Deregulated county, regulated county, and hinterland county

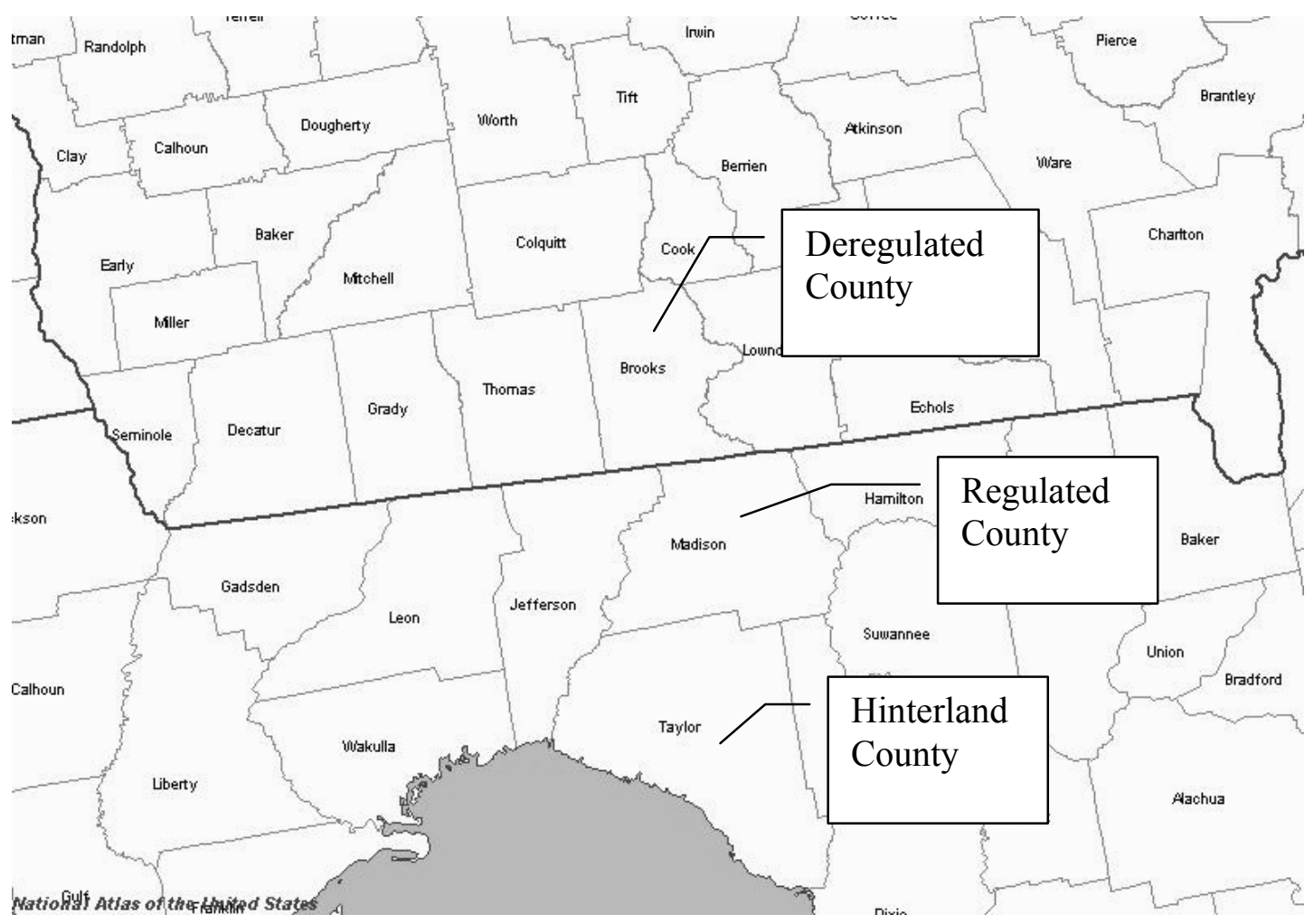

Note: This is a map of the area around the Georgia-Florida border. Georgia removed restrictions on statewide branching in 1983, whereas Florida removed them in 1988. Thus, there were regulatory differences across the Georgia-Florida border during the 1983-1988 period. An example is given in the map: Brooks county in Georgia is the so-called deregulated county, Madison county in Florida is the so-called regulated county, and Taylor county also in Florida is the so-called hinterland county. See Section 2 for details.

\section{Methodology: Estimating the Treatment Effects}

\subsection{Collapsing of information into "pre-" and "post-" period}

A difference-in-differences methodology compares outcomes in the treatment group and the control group, in the "pre-" and "post-" treatment periods to identify the treatment effects. This study defines the two periods as follows:

(1) "Pre-" Period: In this period, both states restricted intrastate branching. The "pre-" treatment period is defined as a ten-year period before one of the two 
states first removed the restrictions. Thus, there were no treatments during this period. For states that deregulated before 1979, this period is shorter than ten years, as county-level income growth data are available only from 1969.

(2) "Post-" Period: In this period, one of the two states was deregulated, but the other state remained regulated until much later. In this period, there were regulatory differences across state borders, and thus, one state received treatment while the other did not. When Iowa is used in the comparisons as the regulated state, we end the "post-" period in $1994 .{ }^{13}$

To estimate the economic effect of deregulation, Jayaratne and Strahan (1996) use a panel data set pooling yearly time-series information. However, Bertrand, Duflo, and Mullainathan (2004), show that difference-in-differences estimation that uses many years of data and focuses on serially correlated outcomes does not produce consistent standard errors. Bertrand et al find an effect significant at the 5\% level for up to $45 \%$ of the placebo treatments, which clearly rejects the validity of the standard errors. Furthermore, Bertrand et al do not find econometric corrections that place a specific parametric form on the time-series process to be able to correct the problem. Nevertheless, they do show that collapsing the time series information into a "pre-" and "post-" period works well.

As a basic but first and necessary step to avoid potentially inflating the statistical significance of the treatment effects, we follow exactly this prescription and study a treatment effect that is defined as difference-in-differences of average annual growth rates $(\%)$ between the "pre-" and "post-" periods, and between treatment and control

\footnotetext{
${ }^{13}$ Iowa eventually removed statewide branching restrictions completely in 2001 . We end the comparison in 1994 when the Riegle-Neal Interstate Banking and Branching Efficiency Act (IBBEA) was passed because by then, all of the other states had already permitted intrastate branching, and the year is generally regarded as the completion date of geographic banking deregulations in the United States.
} 
counties on opposite sides of regulation change borders. The treatment effect (TE), i.e., "growth acceleration gap" between two contiguous counties, is thus measured by:

$$
T E=\left(g_{1, p o s t}-g_{1, p r e}\right)-\left(g_{0, p o s t}-g_{0, p r e}\right)
$$

where $g_{l}\left(g_{0}\right)$ is the average annual growth rate of real per capita income in the county that removed branching restrictions earlier (later), while subscripts "pre-" and "post-" denote the "pre-" and "post-" periods, respectively. Per capita personal income data at county level were obtained from the Regional Economic Information System (REIS) of the Bureau of Economic Analysis (BEA). Real growth rates are obtained by deflating the nominal income data with the national consumer price index obtained from the Bureau of Labor Statistics (BLS).

The hypothesis of the study is: If a certain bank branching deregulation has any positive effect on the local economy, one should observe that deregulated counties experience a greater growth acceleration in the several years after the deregulation compared to their neighbors across the regulation change borders, or in other words, we should find the treatment effect (i.e., the growth acceleration gap) to be significantly positive, both economically and statistically.

There are two steps we need to go through before we can establish whether growth acceleration actually takes place after a specific event of deregulation. First, we need to correct bias in the point estimate of treatment effect. Second, we need to know the estimation procedure's correct standard errors in order to establish statistical significance of the treatment effects. The second step is the most important and challenging part of the exercise. But let's start from the easier one first. 


\subsection{Correcting bias in the point estimate of treatment effects (TE)}

To correct bias in the point estimate of treatment effects, we need to control for factors that could be correlated with both the deregulation event and future growth. These factors could be observable or unobservable, time-invariant or time-varying.

The use of contiguous counties has helped us minimize the influence of unobservable (to econometricians) factors, because contiguous counties are arguably similar in a lot of unobservable factors, although it is difficult for econometricians to verify it formally--otherwise they are observable in the first place.

Furthermore, any observable or unobservable factors that affect growth, if they are time-invariant, should not bias the point estimate of the difference-in-differences treatment effects; because in the treatment effect's definition $T E=\left(g_{1, \text { post }}-g_{1, \text { pre }}\right)-\left(g_{0, \text { post }}-g_{0, \text { pre }}\right)$, if a certain time-invariant, county-specific factor affects growth, it should have affected $\mathrm{g}_{1 \text {, pre }}\left(\mathrm{g}_{0, \text { pre }}\right)$ as much as it had affected $\mathrm{g}_{1 \text {, post }}\left(\mathrm{g}_{0}\right.$, post), and should have been canceled out already.

Therefore, what remain for us to adjust are those factors that are both observable and likely to be time-varying: We control for two most obvious factors that are likely to affect growth. Below, we will first discuss how they affect growth in general, and then elaborate on the details on how the time-varying components can be incorporated in the estimation of treatment effects.

The first one is income gap, which affects growth difference through the convergence effect. It is defined as the log difference (\%) between two counties' per capita income. If a county that deregulates earlier is poorer compared to its neighbors at the beginning of a period, then it tends to grow faster in the next years, even absent of 
any deregulation effects. Not taking into account this factor would lead us to overestimate the treatment effects. Nevertheless, income gap at the start of the "post-" period alone does not matter to the treatment effects, because if the income gap is as large as it was 10 years before deregulation (i.e., the beginning of the "pre-" period), then the convergence effect would be the same for both periods and should have been canceled out in the difference-in-differences estimate. If the gap has changed during the 10-year period, however, the effect needs to be explicitly controlled for. Thus, the first factor we control for is the change in income gap 10 years before and at the time of the deregulation.

The second important factor that affects growth difference is the growth opportunity gap, which is determined by sector-specific shocks at the regional level (Barro \& Sala-i-Martin, 1992). Sector-specific shocks at the regional level, i.e., regional sectoral growth pattern, affect local growth differentially depending on the local industrial structure. If in a certain region manufacturing grows slower than nonmanufacturing over a period, then a county with less manufacturing share than its neighbors at the beginning of the period tends to grow faster subsequently, even absent of deregulation events. Not taking into account this factor would lead us to overestimate the treatment effects.

Within a county-pair, the growth opportunity gap between two counties over a certain period is defined as the difference in manufacturing income share between the two counties at the beginning of the period, multiplied by regional-level growth rate difference between the manufacturing sector and the non-manufacturing sector, i.e.,

$$
\text { Growth_Opportunity_Gap }=\left(M_{1}-M_{0}\right)\left(G_{M}-G_{S}\right)
$$

where $M_{1}$ is the manufacturing share (ratio) of county 1 , and $M_{0}$ that of county $0 ; G_{M}$ is 
the annual growth rate (\%) of manufacturing in the region, and $\mathrm{G}_{\mathrm{S}}$ that of nonmanufacturing in the region. The derivation of the formula is explained in the footnote. ${ }^{14}$ Sectoral growth data are obtained from the Bureau of Economic Analysis (BEA)'s database. The regional growth rate is defined as the average of the two-state economies in question, and thus, growth opportunity gaps differ for every county-pair. Again, this factor does not matter if (a) industrial structures remain the same 10 years before and at the time of the deregulation; and (b) regional growth patterns are the same in the two periods. What we need to control for, instead, is the change (difference) in growth opportunity gap between the "post-" and "pre-" periods, as time-invariant components are already mechanically removed from the difference-in-differences treatment effects.

\subsection{Establishing correct standard errors of the estimation procedure}

The relatively more difficult part of the exercise is to establish the correct standard error of a treatment effect, or in other words, to find out how large a treatment effect needs to be to qualify as statistically significant growth acceleration. This is a challenging task. OLS standard errors obtained from the in-sample could be biased downward, because neither the research question we study nor the research sample we select are randomly drawn from the population of ideas; or in other words, (purposeful or collective) data snooping could have been practiced to obtain the significant results. As a matter of fact, when we decide to study one particular type of policy change in this paper, i.e., branching deregulations, as opposed to many other numerous potential candidates,

\footnotetext{
${ }^{14}$ The predicted growth rate of county 1 , based on region-wide sectoral-specific shock and local industrial structure, is $M_{1} G_{M}+\left(1-M_{1}\right) G_{s}$, and that for county 0 is $M_{0} G_{M}+\left(1-M_{0}\right) G_{s}$. The "growth opportunity gap" between county 1 and county 0 , thus, is the difference between the two predicted rates:$$
\left[M_{1} G_{M}+\left(1-M_{1}\right) G_{s}\right]-\left[M_{0} G_{M}+\left(1-M_{0}\right) G_{s}\right]
$$$$
=M_{1} G_{M}-M_{1} G_{S}-M_{0} G_{M}+M_{0} G_{s}=\left(M_{1}-M_{0}\right)\left(G_{M}-G_{S}\right)
$$ 
we already make a non-random choice potentially guilty of data-snooping. This problem is particularly severe here because the outcome variable, income growth of US county economies, is widely studied, and the possibility of collective data-snooping cannot be easily ruled out. The presence of spatial correlation within a chain of neighboring countypairs along the same segment of a border further exacerbate the problem because a positive correlation of shocks and treatment effects within a border county chain greatly increases the chance of finding large mean of the treatment effects in a data-mining process. Furthermore, the United States is a collection of diverse regional economies with heterogeneous levels and variance of growth rates, and the branching deregulation events spanned a 15-year period of unprecedented and volatile changes in the banking sector and in the economy. These factors greatly increase the probability of finding large treatment effects through data-mining.

To address the above concerns, we adopt a non-parametric strategy that is used rather routinely in clinical trial studies to establish statistical significance, usually known as randomization (or permutation) test. To implement this method, we will utilize information from the out-of-sample "non-event borders." Other than the 38 segments of regulation change borders used to obtain treatment effects of actual deregulation events, we further identify 32 segments of "non-event borders" (and 266 pairs of contiguous counties), where there are no such dramatic cross-border policy differences as those observed in the "regulation change borders" (i.e., counties on one side of the border deregulate earlier, but counties on the other side do not follow immediately within three years). 
We then randomize (also known as "permutate") fictitious placebo deregulation treatments on these non-event borders and calculate the "treatment effects" for these placebo events based on actual growth rates outcomes as if real deregulations had actually taken place. As a result of these simulations, we are able to obtain an empirical distribution of the "treatment effects when there are no treatments", by exhausting all of the possible fictitious scenarios. Each placebo deregulation is specified as a different combination of the following three parameters: (a) any one county-pair from the nonevent borders, (b) any one year for the deregulation to take place; and (c) either side of the border to receive the deregulation earlier (i.e., which side will be assigned to treatment group and the other to control group). Therefore, the universe of the placebo deregulations can be known by exhausting all of the possible combinations.

Note that, in our preferred procedure (see Section 4.4 for details), to remove the influence of positive spatial correlation of treatment effects within a chain of neighboring county-pairs, in constructing a scenario, instead of a single county-pair we choose to draw a chain of certain number of neighboring county-pairs from a border, and administer the placebo deregulation to all counties on one side of the border chain. Then, the mean treatment effects of these neighboring county-pairs is calculated and retained to form an empirical distribution that has by construction taken into account the spatial correlations of treatment effects among neighboring county-pairs.

Because the placebo deregulations are completely fictitious, the distribution of their "treatment effects" can inform us intuitively: by certain percentage of chance how large (extreme) a treatment effect can be obtained by examining a county-pair randomly drawn from borders where no real treatments are applied in reality. Let's assume the $95^{\text {th }}$ percentile of the distribution is a treatment effect of $+2 \%$ per year, and you, a researcher 
of the data set, are given 20 draws from the universe of possibilities in designing a study and producing an empirical result. Then simply by a five-percentage chance, you could find growth acceleration of such magnitude in 1 of the 20 draws. Similarly, if 20 researchers are mining the same dataset, one of them could by chance identify significant growth accelerations of such magnitude, although no real treatments are actually applied. In this case, only when the treatment effect of an actual event is greater than $+2 \%$ can you firmly acquit the result of data-snooping charge and establish the statistical significance at the $95 \%$ level.

Based on the empirical distribution of treatment effects derived from the randomized simulations, a statistical table of critical values at various confidence levels can be created. Treatment effects estimated from actual deregulation events then can be compared against the corresponding critical values, and exact statistical significance can be established. This statistical table will be useful not only for this particular study, but for future studies that utilize the same empirical setup to examine the economic impacts of many other financial regulations that used to exhibit cross-state differences at certain points in time, which may include personal bankruptcy law, foreclosure law (judicial vs. power-of-sale), predatory lending law (modern version of usury law), depositor preference law, and anti-takeover law, to name just a few obvious subjects of interest to financial economists.

\subsection{Using the non-event sample to correct biases in the point estimate of actual treatment effects}

The non-event borders sample also helps correcting bias in the point estimate of treatment effect. In Section 3.2, we have established that income gap and growth 
opportunity gap can affect growth rate difference, and they need to be controlled for to correct bias in the point estimate of treatment effects. To do this, we will need to run a regression of the raw treatment effects against changes in income gap and growth opportunity gap, and then the residuals of the regression are retained as the adjusted treatment effects. This, however, is yet to be an unbiased point estimate, unless it is estimated on the non-event border sample where deregulations did not actually happen. The reason is that when one runs such a regression on the sample where deregulation actually took place, what one is studying is not how income gap normally affects growth, i.e., whether lower-income counties should grow faster than higher-income counties holding other factors constant. Instead, the coefficient on the income gap will reflect whether deregulations help lower-income deregulated counties more than they help higher-income deregulated counties, conditional on deregulations having taken place and having produced positive effects. Such an interaction effect between the actual occurrence of deregulation event and initial income gap is implicitly installed in the regression model by the sample-selection itself, if the model is estimated on the insample, i.e., where deregulations actually happened.

Our solution to this problem is to conduct a "dry run" on the out-of-sample nonevent borders to obtain the coefficients that truly capture how changes in income gap and growth opportunity gap unconditionally predict treatment effects. The regression is specified as follows (see Section 3.2 for definitions):

Raw Treatment Effect $=\beta_{1} \times$ Change in income gap $+\beta_{2} \times$ Change in growth opportunity gap $+\varepsilon$

Then we will apply the fitted coefficients of Eq. (3) to the actual regulation 
change borders to correct bias in raw treatment effects. The formula is specified as follows, where $\bar{\beta}_{1}$ and $\bar{\beta}_{2}$ are the two fitted coefficients obtained from the regression specified in Eq. (3):

Adjusted Treatment Effect $=$ Raw Treatment Effects $-\bar{\beta}_{1} \times$ Change in income gap

$-\bar{\beta}_{2} \times$ Change in growth opportunity gap

\section{Randomizing Placebo Deregulations on the Non-Event Borders}

In this section, we will implement the empirical strategies introduced in the Section 3. Before working on the regulation change borders and assessing the actual deregulation events, we first need to conduct randomized simulations on the non-event borders to obtain empirical distribution of the treatment effect estimator, as well as the coefficients of Eq.(3), which will be used to correct bias in point estimates.

\subsection{Conducting simulations and obtaining estimates of "treatment effects"}

In the eastern United States (i.e., states to the west of Montana, Wyoming, Colorado, and New Mexico), there are 60 segments of bilateral state borders that can potentially be utilized for the study, of which 38 are so-called regulation change borders according to our definition (i.e., one side of the border deregulated branching earlier, while the other side had not followed within three years). These regulation change borders will be used to assess the real effects of actual deregulation events. The remaining 32 segments of borders are defined as the non-event borders, where such dramatic events as those observed in the regulation change borders did not take place. In Figure 3, the 32 segments of non-event borders are highlighted in the map, and in Table 3, the states forming the bilateral borders are listed. Along these non-event borders, 266 pairs of contiguous counties are identified. 
Table 3: Non-event states used for simulations

\begin{tabular}{lll}
\hline State name & $\begin{array}{l}\text { Number of } \\
\text { county-pairs }\end{array}$ & $\begin{array}{l}\text { Share in the } \\
\text { sample (\%) }\end{array}$ \\
\hline Alabama & 17 & 3.20 \\
Connecticut & 3 & 0.56 \\
Delaware & 11 & 2.07 \\
Georgia & 41 & 7.71 \\
Illinois & 40 & 7.52 \\
Indiana & 38 & 7.14 \\
Iowa & 14 & 2.63 \\
Kentucky & 27 & 5.08 \\
Louisiana & 23 & 4.32 \\
Maryland & 30 & 5.64 \\
Massachusetts & 7 & 1.32 \\
Michigan & 5 & 0.94 \\
Minnesota & 18 & 3.38 \\
Mississippi & 18 & 3.38 \\
Missouri & 19 & 3.57 \\
New Hampshire & 5 & 0.94 \\
New Jersey & 7 & 1.32 \\
New York & 12 & 2.26 \\
North Carolina & 50 & 9.40 \\
Oklahoma & 2 & 0.38 \\
Pennsylvania & 13 & 2.44 \\
Rhode Island & 8 & 1.50 \\
South Carolina & 31 & 5.83 \\
South Dakota & 10 & 1.88 \\
Tennessee & 23 & 4.32 \\
Texas & 11 & 2.07 \\
Vermont & 13 & 2.44 \\
Virginia & 20 & 3.76 \\
West Virginia & 9 & 1.69 \\
Wisconsin & 7 & 1.32 \\
\hline Total & 532 & 100 \\
\hline
\end{tabular}

Note: Thirty-two segments of so-called non-event borders are identified for the study. Placebo deregulations are randomly applied to these borders to obtain fictitious treatment effects. Placebo deregulations can be scheduled to take place earlier on either side of the border. Thirty states are eligible to receive placebo deregulation shock earlier than their neighboring states, and thus, form the treatment group (similarly, in separate scenarios they can be scheduled to receive the treatments later than their neighbors, and thus, form the control group, too.) The names of the states are listed in the table. The second column records the number of county-pairs that can be studied if the corresponding state is slated for an earlier placebo deregulation. Note that the numbers add up to twice the number of county-pairs along the non-event borders, because the deregulations can take place earlier in either side of the border, or in other words, a state can belong to both treatment and control groups in separate scenarios. 
Figure 3: "Non-event borders"

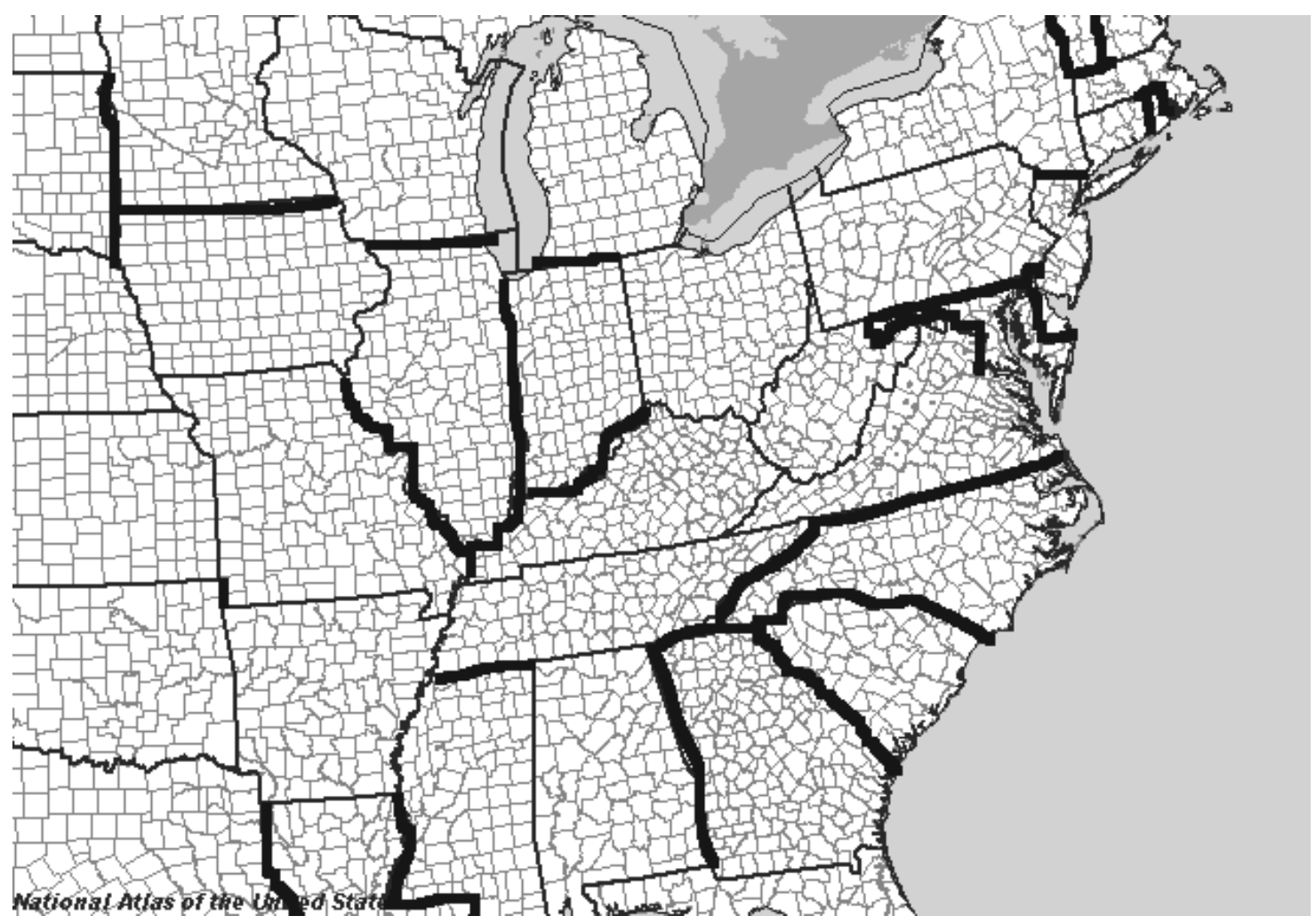

Note: This study identifies 32 segments of so-called non-event borders, which are highlighted in the map below. Across the so-called regulation change borders, for at least three years there were regulatory differences, with commercial banks on only one side of the borders free from restriction on statewide branching. Across these non-event borders, however, there were no such dramatic situations. In the study, fictitious placebo deregulation events are randomly simulated on these borders where treatments do not exist in reality, to obtain an empirical distribution of the fictitious events" "treatment effects," which later can help us distinguish real treatment effects of actual deregulation events from the potential results of data-snooping. The critical values of the distribution at various confidence levels can tell us how easily we can obtain certain large treatment effects through data-snooping on borders where real treatments do not occur in reality. See Section 3 and Section 4 for details.

We will simulate fictitious placebo deregulations on these borders to find out what magnitude of "treatment effects" we could obtain through data snooping, on these borders where differential treatments are not real. This can help us create a benchmark to statistically distinguish real deregulation effects from what can be obtained by data- 
snooping. In constructing a placebo deregulation, we can randomly draw a county-pair from these borders, choose the year for the placebo deregulation, and apply it earlier to one side of the border than the other. And then we will calculate "treatment effect" of this placebo deregulation, using actual realized growth rate data. As a result, we are able to form an empirical distribution of the "treatment effects when treatments are not real" by exhausting all of the possible fictitious scenarios. A placebo deregulation can be produced from the random combination of the following three parameters: (a) any one of the 266 county-pairs; (b) any 1 of the 11 years $(1979-1989)^{15}$; and (c) either side of the border (for the deregulation to take place earlier). Therefore the total number of all possible combinations is 5,852 (i.e., $266 \times 11 \times 2$ ).

The schedules of placebo deregulations are standardized so that the "post-" period lasts for five years, i.e., there is a five-year waiting period before the second state also deregulates branching. This is representative of the actual deregulation schedule in our real sample, in which the median gap is exactly five years. The length of the "post-" period is also similar to that in Jayaratne and Strahan's (1996) sample, which makes the point estimates somewhat comparable across studies, although they use a state as the unit of analysis.

\subsection{Adjusting for the income gap and the growth opportunity gap}

As discussed in Section 3.2, income gap and growth opportunity gap between treatment and control group, if not controlled for, would bias the point estimate of treatment effects. Thus, after each simulation, we calculate not only the raw treatment effects, but also the changes in income gap and growth opportunity gap between the "pre-

\footnotetext{
${ }^{15}$ The "pre-" period is ten years long, and county-level income data are available only after 1969; thus, the placebo deregulation can only take place in or after 1979. Similarly, as the sample period ends at 1994, the last year possible for a placebo deregulation with a five-year "post-" period has to be 1989.
} 
" and "post-" periods. Then we pool together the information of all of the 5,852 simulations, and estimate an OLS regression of the raw treatment effects against changes in income gap and growth opportunity gap, as specified in equation (3). The residuals of the regression are then retained as the adjusted treatment effects.

The regression results are reported as follows, with the estimation standard errors of the coefficients indicated within parentheses. ${ }^{16}$

Raw Treatment Effect $=-0.1294$ (0.0019) $\times$ Change in income gap +0.3816

$$
\left.(0.0559) \times \text { Change in growth opportunity gap } \quad \text { (adjusted } R^{2}=0.45\right)
$$

Note that the standard errors of these OLS coefficients are clearly under-estimated, because a county is used in separate scenarios for many times, and thus, included for multiple times in the regression sample. We do not attempt to correct the standard errors, as only the point estimates of the coefficients, which are not contaminated, will be used in this paper.

The negative coefficient on income gap confirms that if the income gap between two contiguous counties widens (assuming that the deregulated county is initially poorer) during the 10-year period before the deregulation happens, then the raw treatment effect will be biased upward because the convergence effect becomes greater and the deregulated counties will naturally tend to speed up. Without adjusting for this factor, we could identify a positive treatment effect for the deregulated county, even when the placebo deregulation has no effects.

\footnotetext{
${ }^{16}$ By construction of the simulations, i.e., a county is used as both treatment and control groups (in separate simulation scenarios), the coefficient on the constant of the regression will always be zero when it is estimated based on the population of all 5,582 possible scenarios. For the same reason, both of the two control variables, change in income gap and change in growth opportunity gap, have zero as their means. The standard deviation of "change in income gap" is $10.8 \%$, while that for "change in growth opportunity gap" is 0.366 .
} 
The positive coefficient on growth opportunity gap confirms that change in either local industrial structure or regional growth pattern/trend has important impacts on future growth. If county A has a lower manufacturing share than its neighbor's, and this remains unchanged 10 years before and at the time of deregulation, but regional manufacturing grows slower than non-manufacturing in the "post-" period than in the "pre-" period, then county A will naturally tend to grow faster even in the absence of a deregulation. Similarly, if the regional growth pattern remains unchanged in the "pre-" and "post-" periods (and manufacturing grows slower than non-manufacturing), but county A's manufacturing share drops even further during the 10-year pre-period; then subsequently after deregulation, county A will naturally accelerate further even absent of the deregulation effect, as its growth opportunity is getting better.

\subsection{Creating the statistical table of critical values for the treatment effect estimator}

The residuals obtained from regression (5) are used as the adjusted treatment effects of the placebo deregulation events. Each residual value is linked to an individual placebo treatment. In Figure 4, the whole distribution of the residuals is presented in a histogram. As the placebo deregulations are completely fictitious, the reference distribution can tell us, in the absence of real treatments, how easily we will encounter a certain large (extreme) treatment effects when there are actually no treatments at all. Note that by construction (that a placebo deregulation could occur earlier in both side of the border, in separate simulation scenarios), the two-tails distribution of the fictitious treatment effects obtained from the population of placebo simulations is always symmetrical with zero as the mean. 
Figure 4: Empirical distribution of fictitious treatment effects obtained from the placebo deregulation events

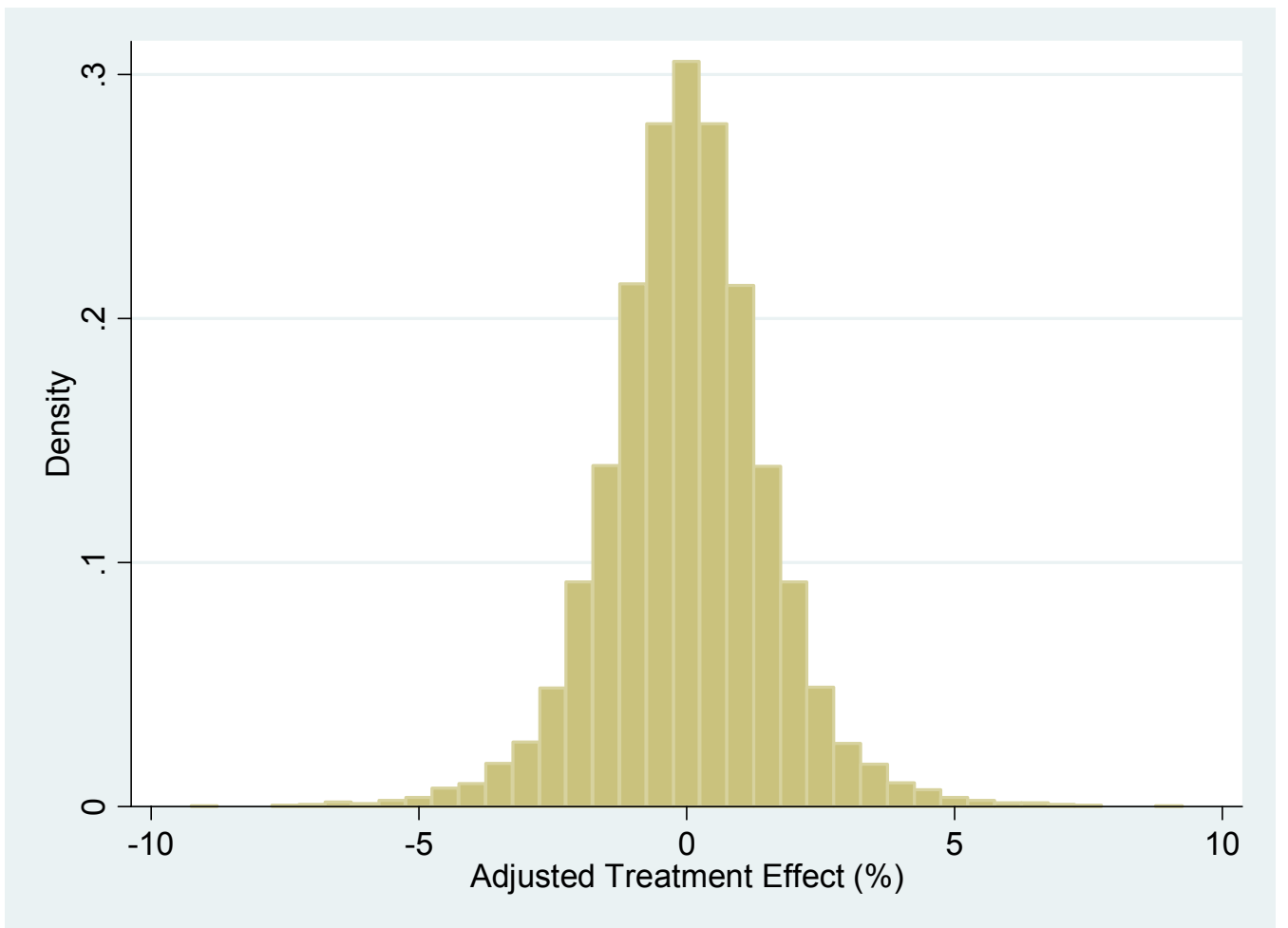

Note: In the study, fictitious placebo deregulations are randomized on the non-event borders, and then adjusted treatment effect is calculated based on actual growth realization data, for each of the 5,852 fictitious deregulation events. The distribution of the fictitious treatment effects is presented in the form of a histogram. Because the placebo deregulations are completely fictitious, the distribution depicted here can reveal, by a certain percentage of chance, how large a fictitious treatment effect can be obtained by randomly selecting a county-pair from the non-event borders and calculating the treatment effect based on actual growth rates data as if the treatment were real. See Section 4.3 for details. The bin size of the histogram is $0.5 \%$.

The distribution in Figure 4 tells us that when studying a non-event border along which there is only one county-pair, there is a $10 \%$ random chance that we could find treatment effects (growth acceleration) greater than $1.82 \%$, even in the absence of any actual occurrence of treatments on one side of the border. This means that when evaluating an actual deregulation event, if there is only one county-pair along the regulation change border, and the point estimate of the treatment effect is $1.81 \%$, we still 
cannot establish at $90 \%$ confidence level that statistically significant growth acceleration actually occurs in this particular deregulation event, because even in the non-event borders where there are no real treatments, there is more than a $10 \%$ chance we can randomly run into treatment effects of such a magnitude. In Table 4 , a table of critical values for various confidence levels is created based on the empirical distribution of fictitious treatment effects. According to the empirical distribution, when the treatment effect is estimated based on a single county-pair, the critical value of treatment effects for p-value $0.10,0.05,0.01$ is $\mathrm{K}_{0.10,1}=1.82 \%, \mathrm{~K}_{0.05,1}=2.45 \%$, and $\mathrm{K}_{0.01,1}=4.20 \%$, respectively. 
Table 4: Statistical table of critical values for the mean treatment effects (not yet adjusted for spatial correlations)

\begin{tabular}{|c|c|c|c|}
\hline \multirow{2}{*}{$\begin{array}{l}\text { Number of } \\
\text { county-pairs } \\
\text { used to form } \\
\text { the mean }\end{array}$} & \multicolumn{3}{|c|}{$\begin{array}{c}\text { Statistical Confidence level } \\
\text { (p-value) }\end{array}$} \\
\hline & $\begin{array}{r}90 \% \\
(0.10)\end{array}$ & $\begin{array}{r}95 \% \\
(0.05)\end{array}$ & $\begin{array}{r}99 \% \\
(0.01)\end{array}$ \\
\hline 1 & 1.82 & 2.45 & 4.20 \\
\hline 2 & 1.28 & 1.73 & 2.97 \\
\hline 3 & 1.05 & 1.42 & 2.42 \\
\hline 4 & 0.91 & 1.23 & 2.10 \\
\hline 5 & 0.81 & 1.10 & 1.88 \\
\hline 6 & 0.74 & 1.00 & 1.71 \\
\hline 7 & 0.69 & 0.93 & 1.59 \\
\hline 8 & 0.64 & 0.87 & 1.48 \\
\hline 9 & 0.61 & 0.82 & 1.40 \\
\hline 10 & 0.57 & 0.78 & 1.33 \\
\hline 11 & 0.55 & 0.74 & 1.26 \\
\hline 12 & 0.52 & 0.71 & 1.21 \\
\hline 13 & 0.50 & 0.68 & 1.16 \\
\hline 14 & 0.49 & 0.66 & 1.12 \\
\hline 15 & 0.47 & 0.63 & 1.08 \\
\hline 16 & 0.45 & 0.61 & 1.05 \\
\hline 17 & 0.44 & 0.59 & 1.02 \\
\hline 18 & 0.43 & 0.58 & 0.99 \\
\hline 19 & 0.42 & 0.56 & 0.96 \\
\hline 20 & 0.41 & 0.55 & 0.94 \\
\hline 25 & 0.36 & 0.49 & 0.84 \\
\hline 30 & 0.33 & 0.45 & 0.77 \\
\hline 35 & 0.31 & 0.41 & 0.71 \\
\hline 40 & 0.29 & 0.39 & 0.66 \\
\hline 45 & 0.27 & 0.37 & 0.63 \\
\hline 50 & 0.26 & 0.35 & 0.59 \\
\hline
\end{tabular}

Note: Along the 32 segments of non-event borders, randomized simulations let fictitious placebo deregulations take place on any of the 266 pairs of contiguous border counties, in any one year between 1979 and 1989. Once the state to be scheduled for an earlier placebo deregulation is selected (either side of the border can be selected), counties on the other side of the state border will be scheduled to deregulate five years later. Then, the raw treatment effects will be calculated based on the difference-in-differences of average annual growth rate between "post-" and "pre-" period and between the two contiguous counties. The "adjusted treatment effect" is then obtained by taking the residuals from a regression of raw treatment effect on change in income gap and growth opportunity gap between the "post-" and "pre-" period.

An empirical distribution of the placebo deregulations' treatment effects is obtained based on all 5,852 possible scenarios. As the placebo deregulations are completely fictitious, the distribution can inform us: by a certain percentage of chance how large a "treatment effect" we could obtain by randomly selecting a county-pair from borders where cross-border differential treatments did not occur in reality. In actual events of deregulations, along a border there are multiple pairs of contiguous counties. Assuming no spatial correlations of treatment effects within a chain of neighboring county-pairs along the same segment of a border, the critical values for the mean 
treatment effects can be extrapolated from the single county-pair case by the formula: $\mathrm{K}_{\mathrm{N}}=\mathrm{K}_{1} / \mathrm{SQRT}(\mathrm{N})$, where $\mathrm{N}$ is the number of county-pairs used to form the mean, and $\mathrm{K}$ is the critical value. To save space, for $\mathrm{N}>20$, critical values are reported in the table only for the multiples of $5 \mathrm{~s}$.

Let's take an actual deregulation event as an example to illustrate how the table is used to distinguish real treatment effects from the results of data-snooping. In the case of Illinois, there are nine pairs of contiguous border counties, and the mean adjusted treatment effect of this deregulation event turns out to be 0.46 . Checking the table of critical values, in the row corresponding to the case of " 9 county-pairs", we find three critical values, 0.61 for $90 \%, 0.82$ for $95 \%$, and 1.40 for $99 \%$ confidence level. Since the actual treatment effect 0.46 is smaller than 0.61 , it is established that in the case of Illinois, significant treatment effect cannot be established statistically in the years surrounding the deregulation event. The reason is that even by datasnooping, in more than $10 \%$ of chance you can find a mean treatment effect greater than 0.61 if 9 independent county-pairs are drawn from borders where such differential treatments did not occur in reality. See Section 4.3 for details.

However, in actual deregulation events, along a regulation change border, we usually use more than one county-pair to form the mean treatment effect. Thus, we also need to obtain the critical values for the mean treatment effect of an N-observations sample when $\mathrm{N}>1$. Assuming that the treatment effect of each individual county-pair along a regulation change border is independent of its neighboring county-pairs along the same segment of the border, the critical values for the mean treatment effect of an $\mathrm{N}$ observations sample can be analytically extrapolated from the case of one single countypair. Specifically, the critical values for the mean treatment effect based on $\mathrm{N}$ observations of county-pairs would be $K_{p, n}=K_{p, 1} / \sqrt{N}$, where $p$ indicates the p-value. It is easy to see that the critical values for mean treatment effects drop as the number of county-pairs increases for a specific deregulation event.

The critical values for $\mathrm{N}=1,2, \ldots, 50$ presented in Table 4 are calculated this way. The values suggest that, for example, if there are 10 county-pairs along a specific regulation change border, then we require the mean treatment effect of the 10 countypairs to be greater than $2.45 \% / \sqrt{10}=0.78 \%$ to be statistically significant at the $95 \%$ level. 
If there are 20 county-pairs, however, the threshold critical value will be lowered to $2.45 \% / \sqrt{20}=0.55 \%$

In Section 4.4, we will drop the assumption of spatial independence, and analyze how this effect would change the critical values.

\subsection{Taking into account spatial correlations of treatment effects}

The critical values produced in the last section for $\mathrm{N}>1$ samples are unbiased only when we can assume that there are no correlations of treatment effects within a chain of neighboring county-pairs along the same segment of a border. If this were the case, then treatment effects obtained from each of the $\mathrm{N}$ county-pairs would be independent, and it would be valid to use the extrapolated critical values produced in the last section to the mean of the $\mathrm{N}$ treatment effects.

Spatial correlation, however, is typically present in the empirical setting of this study. Treatment effects for two pairs of counties next to each other are likely to be positively correlated, as counties on the same side of the regulation change border receive (or delay to receive) the same state-specific policy shocks. Not accounting for this factor would lead us to underestimate the standard errors of the mean treatment effects.

Again, we will use randomized simulations to empirically solve the problem. In the last section, we randomly draw one single county-pair in each simulated scenario, form the reference distribution of treatment effects, obtain critical values for the $\mathrm{N}=1$ case, and then extrapolate them to the mean treatment effects of $\mathrm{N}>1$ cases using the formula $K_{n}=K_{1} / \sqrt{N}$, assuming that treatment effects for neighboring county-pairs along a border are independent of each other. In the new series of placebo deregulations, in each 
of them, instead of an individual county-pair we draw a chain of $\mathrm{N}(\mathrm{N}>1)$ neighboring county-pairs along a border, and as usual choose the year of deregulation, and select which side of the border is to receive the deregulation first. The treatment effect is calculated in the same way as in the case of single county-pair. What differs is that now we will calculate and retain the mean of the treatment effects of the $\mathrm{N}$ neighboring county-pairs (when $\mathrm{N}>1$ ).

We simulate all possible combinations (scenarios), and repeat the procedure for different $\mathrm{N}$ values (the length of the chains of neighboring county-pairs). As $\mathrm{N}$ increases, the number of possible combinations (and thus, draws of simulations) is reduced, because there are fewer non-event borders where longer chain of neighboring counties can be sampled.

As the products of the simulations, we obtain 50 empirical distributions of mean treatment effects, for $\mathrm{N}=1,2, \ldots, 50$, respectively. Based on these distributions, we can then empirically establish a table of critical values that are free from the influence of spatial correlations of treatment effects within a chain of neighboring county-pairs, without knowing the precise model of the spatial dependence. The table of critical values is presented in Table 5, for sample size from 1 to 50 . To illustrate the changes in critical values after taking into account spatial correlations, Figure 5 plots two curves based on the two groups of critical values, with only one taking into account spatial correlations. The comparison clearly reveals the severe downward bias of standard errors when positive spatial correlations are not taken into account. 
Table 5: Statistical table of critical values for the mean treatment effects (robust to spatial correlations)

\begin{tabular}{|c|c|c|c|c|}
\hline \multirow{2}{*}{$\begin{array}{l}\text { Number of } \\
\text { county-pairs } \\
\text { used to form } \\
\text { the mean }\end{array}$} & \multirow[b]{2}{*}{$\begin{array}{c}\text { Number of } \\
\text { simulations } \\
\text { conducted }\end{array}$} & \multicolumn{3}{|c|}{$\begin{array}{c}\text { Statistical Confidence level } \\
\text { (p-value) }\end{array}$} \\
\hline & & $\begin{array}{r}90 \% \\
(0.10)\end{array}$ & $\begin{array}{r}95 \% \\
(0.05)\end{array}$ & $\begin{array}{r}99 \% \\
(0.01)\end{array}$ \\
\hline 1 & 5,852 & 1.82 & 2.45 & 4.20 \\
\hline 2 & 5,423 & 1.51 & 2.02 & 3.32 \\
\hline 3 & 5,005 & 1.36 & 1.82 & 2.94 \\
\hline 4 & 4,631 & 1.25 & 1.63 & 2.80 \\
\hline 5 & 4,268 & 1.16 & 1.51 & 2.50 \\
\hline 6 & 3,905 & 1.12 & 1.43 & 2.44 \\
\hline 7 & 3,575 & 1.05 & 1.34 & 2.34 \\
\hline 8 & 3,300 & 1.01 & 1.26 & 2.22 \\
\hline 9 & 3,047 & 0.94 & 1.23 & 2.08 \\
\hline 10 & 2,805 & 0.89 & 1.16 & 1.91 \\
\hline 11 & 2,574 & 0.85 & 1.11 & 1.68 \\
\hline 12 & 2,354 & 0.82 & 1.06 & 1.59 \\
\hline 13 & 2,167 & 0.81 & 1.03 & 1.51 \\
\hline 14 & 2,002 & 0.80 & 1.03 & 1.45 \\
\hline 15 & 1,859 & 0.77 & 1.02 & 1.40 \\
\hline 16 & 1,727 & 0.75 & 1.01 & 1.35 \\
\hline 17 & 1,595 & 0.72 & 0.99 & 1.30 \\
\hline 18 & 1,463 & 0.70 & 0.96 & 1.24 \\
\hline 19 & 1,364 & 0.69 & 0.92 & 1.19 \\
\hline 20 & 1,287 & 0.67 & 0.91 & 1.13 \\
\hline 25 & 902 & 0.65 & 0.78 & 0.97 \\
\hline 30 & 539 & 0.65 & 0.74 & 0.95 \\
\hline 35 & 297 & 0.63 & 0.73 & 0.89 \\
\hline 40 & 143 & 0.64 & 0.69 & 0.80 \\
\hline 45 & 66 & 0.51 & 0.54 & 0.65 \\
\hline 50 & 11 & 0.50 & 0.55 & 0.55 \\
\hline
\end{tabular}

Note: Along the 32 segments of non-event borders, randomized simulations let fictitious placebo deregulations take place on any of the 266 pairs of contiguous border counties, in any one year between 1979 and 1989. Once the state to be scheduled for an earlier placebo deregulation is selected (either side of the border can be selected), counties on the other side of the state border will be scheduled to deregulate five years later. Raw treatment effects will be calculated based on the difference-in-differences of average annual growth rate between the "post-" and "pre-" period and between the two contiguous counties. The "adjusted treatment effect" is then obtained by taking the residuals from a regression of raw treatment effect on change in income gap and growth opportunity gap between the "post-" and "pre-" periods.

Spatial correlation of treatment effects exists within a chain of neighboring county-pairs along the same segment of a border. To make the procedure robust to such spatial dependences, we draw at each simulation a chain of $\mathrm{N}$ neighboring county-pairs instead of a single individual county-pair. Simulations are done for $\mathrm{N}$-observation chains $(\mathrm{N}=1,2, \ldots, 50$, respectively). After simulating all possible scenarios (the number of scenarios varies depending on $\mathrm{N}$, the length of the chain), an empirical distribution of the mean treatment effects can be obtained. Fifty such distributions are 
obtained, for $\mathrm{N}=1,2, \ldots, 50$, respectively. As the placebo deregulations are completely fictitious, the 50 empirical distributions can inform us, by a certain percentage of chance how large a mean treatment effect we can obtain by randomly selecting a chain of $\mathrm{N}(\mathrm{N}=1,2, \ldots, 50)$ county-pairs from borders where cross-border differential treatment did not occur in reality. To save space, for $\mathrm{N}>20$, critical values are reported in the table only for the multiples of $5 \mathrm{~s}$.

Let's take an actual deregulation event as an example to illustrate how the table is used to distinguish real treatment effects from the results of data-snooping. In the case of Illinois, there are nine pairs of contiguous border counties, and the mean adjusted treatment effect of this deregulation event turns out to be 0.46 . Checking the table of critical values, in the row corresponding to the case of 9 observations, we find three critical values, 0.94 for $90 \%, 1.23$ for $95 \%$, and 2.08 for $99 \%$ confidence level. Since the actual treatment effect 0.46 is smaller then 0.94 , in the case of Illinois, significant treatment effect cannot be established statistically in the years surrounding the deregulation. The reason is that even by data-snooping, by a greater than $10 \%$ random chance, a mean treatment effect greater than 0.61 can occur if a chain of 9 neighboring county-pairs is drawn from borders where treatments did not actually occur in reality. See Section 4.4 for details.

Figure 5: Empirical critical values of mean treatment effects: Before and after adjusted for spatial correlations

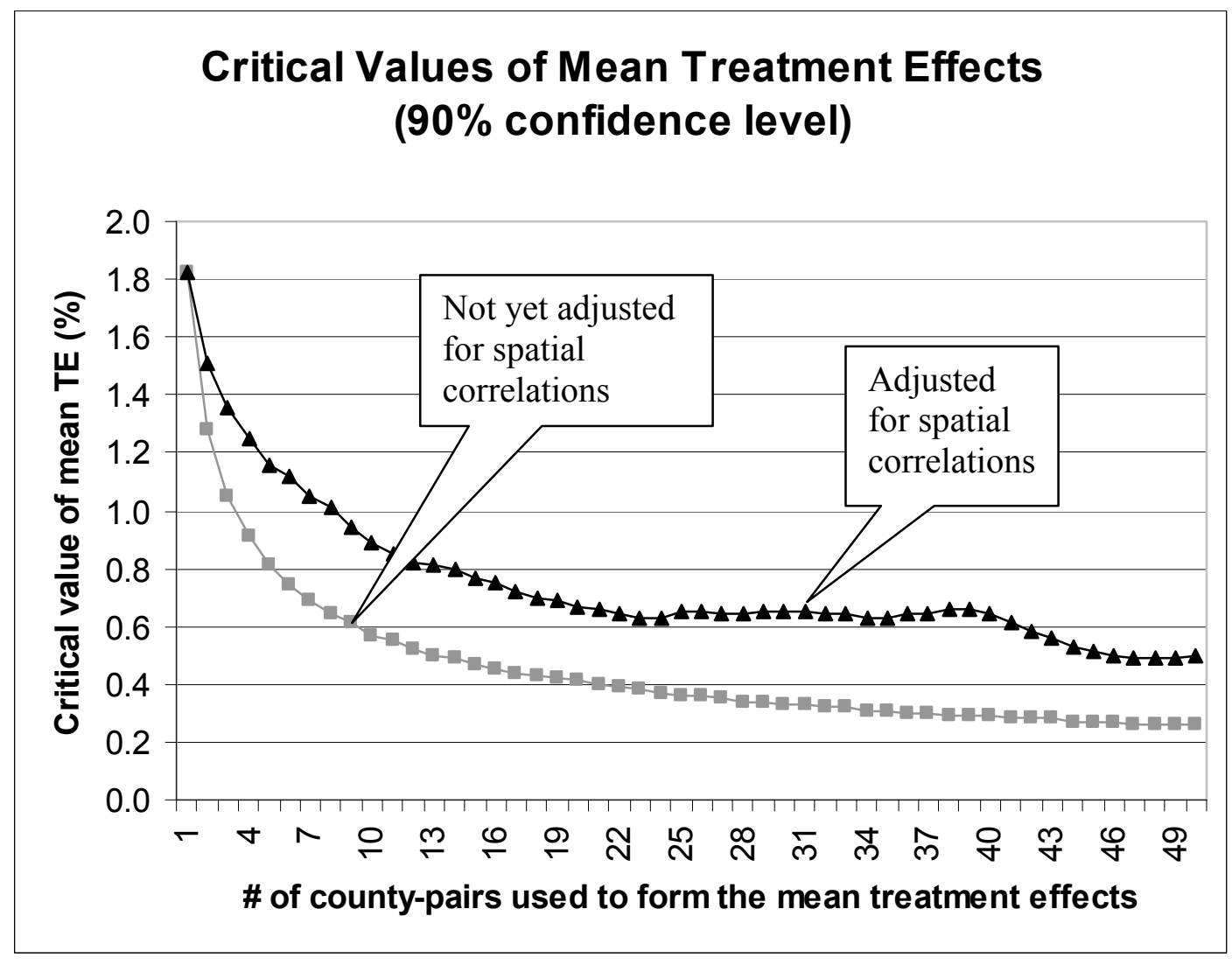

Note: In the study, we use placebo deregulations to create critical values for the mean treatment effects, to distinguish real treatment effects from the results of data-snooping. The critical values at various confidence levels can tell us, by a certain percentage of chance, how large a mean 
treatment effect we could obtain from data-snooping on the non-event borders where deregulations do not take place in reality; and thus, when one obtains a mean treatment effect from an actual deregulation event that actually occurs, how likely it is the result of data-snooping vs. genuine treatment effects. When the number of county-pairs used to evaluate a deregulation event is greater than one, the standard errors of mean treatment effects could be biased downwards by positive spatial correlations of treatment effects among neighboring county-pairs within a regulation change border. We rely on randomized simulations to adjust for spatial dependence. In the simulations, we apply placebo deregulations to a chain of $\mathrm{N}$ neighboring county-pairs instead of to an individual county-pair. The empirical distribution of mean treatment effects obtained from such simulations, thus, is robust to the influence of spatial correlations. In the chart, we present the critical values of treatment effect estimates before and after they have been adjusted for spatial correlations. It is clear from the chart that we would understate the estimation standard errors had we not adjusted for positive spatial correlations. See Section 4.4 for details.

We take $\mathrm{N}=10$ as an example to illustrate the difference between the two tables of critical values (one does not adjust for spatial dependence, and the other does), and how the table of critical values can be used to assess treatment effects of actual deregulations. Not considering spatial correlation of treatment effects, when 10 independent countypairs are randomly drawn from the non-event borders, it is expected that the mean treatment effects will be greater than $2.45 \% / \sqrt{10}=0.78 \%$ in $5 \%$ of the time, according to the first table of critical values (Table 4) produced in Section 4.3. However, when a chain of 10 neighboring counties along a border is drawn (which is what happens when we evaluate actual deregulations), according to the second table of critical values (Table 5), $5 \%$ of chance actually exists that a mean treatment effect greater than $1.16 \%$ will be found. The comparison shows that positive spatial correlations of treatment effects, if not taken into account, would substantially bias the standard errors downwards. In the rest of the paper, we will mainly use Table 5 to evaluate statistical significance of the estimated treatment effects. 


\section{Evaluating Twenty-Three Actual Events of Deregulations}

After obtaining a statistical table (Table 5) of critical values that are robust to spatial correlation of treatment effects, we are ready to perform assessments on each of the 23 actual events of branching deregulations identified in Section 2. The critical values indicate that, for a treatment effect of an actual deregulation event to be statistically significant at the $95 \%$ level, the magnitude of the effect must be greater than the fictitious treatment effects obtained in $95 \%$ of the placebo deregulations described in Section 4.

In Table 6, some descriptive statistics are presented for the treatment group (deregulated counties), the first control group (border regulated counties), and the second control group (hinterland counties), respectively, on several variables of interest, including the means and medians of growth rates, income per capita, and manufacturing share. The averages and medians are calculated by pooling all county-pairs used in the study, from all 23 events of deregulations, and serve to help readers gain an overall picture of the range of average growth rate in the "pre-" and "post-" periods. Assessments, however, will be conducted separately for each individual deregulation event. Pooling will obscure the important idiosyncratic information of each individual event, because Wall (2004) already shows that the deregulation effects are quite heterogeneous across individual events, which spanned two decades of radical changes in the banking sector, and took place in different locations under different circumstances. Unlike previous studies, we have the luxury of studying individual events separately because the use of county as unit of analysis has increased the degree of freedom in our estimations. 
Table 6: Summary statistics of the county economies (treatment vs. control)

\begin{tabular}{|c|c|c|c|c|c|c|}
\hline \multirow[b]{3}{*}{$\begin{array}{l}\text { Number of } \\
\text { observations }\end{array}$} & \multicolumn{2}{|c|}{$\begin{array}{l}\text { Treatment group: } \\
\text { deregulated counties }\end{array}$} & \multicolumn{2}{|c|}{$\begin{array}{l}\text { First control group: } \\
\text { border-regulated } \\
\text { counties }\end{array}$} & \multicolumn{2}{|c|}{$\begin{array}{l}\text { Second control } \\
\text { group: hinterland- } \\
\text { regulated counties }\end{array}$} \\
\hline & Mean & Median & Mean & Median & Mean & Median \\
\hline & 285 & 285 & 285 & 285 & 249 & 249 \\
\hline $\begin{array}{l}\text { Average growth rate } \\
\text { in "pre-" period }(\%)\end{array}$ & 1.74 & 1.69 & 1.75 & 1.67 & 1.66 & 1.49 \\
\hline $\begin{array}{l}\text { Average growth rate } \\
\text { in "post-" period" (\%) }\end{array}$ & 1.40 & 1.34 & 0.99 & 1.00 & 1.07 & 0.92 \\
\hline $\begin{array}{l}\text { Within } \\
\text { "Acceleration" (\%) }\end{array}$ & -0.34 & -0.06 & -0.76 & -0.57 & -0.59 & -0.56 \\
\hline $\begin{array}{l}\text { Standard deviation of } \\
\text { these "accelerations" }\end{array}$ & $(2.50)$ & & $(2.30)$ & & $(2.36)$ & \\
\hline $\begin{array}{l}\text { Income per capita (at } \\
\text { the time of } \\
\text { deregulation, in } 1980 \\
\text { USD) }\end{array}$ & 8,538 & 8,398 & 8,529 & 8,486 & 8,306 & 8,126 \\
\hline $\begin{array}{l}\text { Manufacturing } \\
\text { income share at the } \\
\text { time of deregulation } \\
\text { (ratio) }\end{array}$ & 0.26 & 0.25 & 0.28 & 0.28 & 0.27 & 0.27 \\
\hline
\end{tabular}

Note: For the actual deregulations events, 285 pairs of contiguous border counties can be examined. Using hinterland counties as the second control group, the number of pairs is reduced to 249 , because no proper hinterland counties can be found for some treatment counties. The Table presents the average (and median) growth rates, in the pre-deregulation period and in the post-deregulation period, and the difference between the two, i.e., the "within" treatment effect (not difference-in-differences treatment effect), for the treatment group (deregulated counties), first control group (border regulated counties), and second control group (hinterland regulated counties), respectively. The Table also presents the mean (median) income per capita and manufacturing income share at the time of deregulation. All of the 23 deregulation events are pooled together to produce the summary statistics in the table for the purpose of helping readers gain an overall understanding of the characteristics of the county economies examined in the study. The state-level deregulations spanned two decades of radical changes in the banking sector and their effects were heterogeneous across events; therefore, whether a significant growth acceleration had actually occurred after a specific deregulation event must be evaluated separately, in light of the heterogeneity of results among deregulation events taking place in different years during a nearly two-decade period. The detailed assessment results are presented in Tables VII and VIII. 


\subsection{Obtaining point estimates of treatment effects}

We first need to obtain a correct point estimate of mean treatment effect for each actual deregulation event, adjusted for biases potentially created by, as discussed in Section 3.2, change in income gap and change in growth opportunity gap between the "pre-" and "post-" periods. As discussed in Section 3.4, for the adjustment to truly reflect effects unrelated to the deregulation itself, we will apply the fitted coefficients obtained from the non-event sample.

A narrowed income gap or widened growth opportunity gap over the 10-year period before deregulation, if not adjusted, could create upward bias for the point estimate of treatment effect. The following formula based on coefficients obtained from Eq. (5) in Section 4.2 can help us correct for the biases.

Adjusted Treatment Effect $(T E)=$ Raw TE $+0.1294 \times$ change in income gap $0.3816 \times$ change in growth opportunity gap

The coefficients are obtained from the non-event sample. Note that had we estimated and used the coefficients based on the in-sample, i.e., where actual deregulations took place, the coefficients would be contaminated by the sample-selection problem discussed in Section 3.4.

The mean treatment effect of a deregulation event is estimated based on 12 county-pairs on average. This truly raises the degree of freedom in estimation and reduces standard errors of the point estimates. In Jayaratne and Strahan (1996), and other similar studies that use state as the unit of analysis, only one treated subject (state) can be evaluated for each deregulation event. To nominally raise degree of freedom and reduce estimation standard errors of OLS coefficients, they typically had to pool together all 
times-series information and all deregulation events. This strategy has a potential problem: Bertrand et al. (2004) show that by pooling serially correlated time-series information, the standard errors are likely to be understated, even after autocorrelation is explicitly modeled. Furthermore, Wall (2004) points out that the pooling of different deregulation events assumes homogeneity of the treatment effects, which he shows to be actually quite heterogeneous across events. Nevertheless, Jayaratne and Strahan do stress that, based on their estimation methodology, it is a general phenomenon, not driven by individual cases, that deregulated states grew relatively faster after deregulation as compared to control states that at first had not yet deregulated. They show that, of the 35 states that deregulated since 1972, all but 6 states performed better (but not necessarily statistically significantly) than the corresponding control states. The six exceptions were New Hampshire, Florida, Michigan, Kansas, Colorado, and New Mexico.

In Table 7, we report, for each of the 23 actual deregulation events, the mean treatment effects (both raw and adjusted), the number of observations (i.e., number of county-pairs) used to form the mean treatment effects, and the average growth rate of the deregulated counties in the "pre-" period. According to the results, the point estimates of the treatment effects are quite heterogeneous across individual deregulation events, which confirms Freeman (2002) and Wall's (2004) findings. In 7 out of the 23 events examined in the study, the treatment effects are actually negative (Maine, Connecticut, Pennsylvania, Georgia, Kansas, Texas, and Wisconsin). In another two cases (New York and Ohio), the positive treatment effects are as small as $0.01 \%$. Among these nine cases, only Kansas is indicated by Jayaratne and Strahan (1996) to have grown slower after deregulation, compared to control states. 
Table 7: Evaluating the actual deregulations events using the contiguous counties as the control group

\begin{tabular}{lcccccc}
\hline \hline $\begin{array}{l}\text { Deregulation } \\
\text { state }\end{array}$ & $\begin{array}{l}\text { First year of } \\
\text { deregulation }\end{array}$ & $\begin{array}{l}\text { Number of } \\
\text { county- } \\
\text { pairs }\end{array}$ & $\begin{array}{l}\text { Mean average } \\
\text { growth rate in } \\
\text { "pre-" period } \\
\text { (\%) }\end{array}$ & $\begin{array}{l}\text { Mean raw } \\
\text { treatment } \\
\text { effect (\%) }\end{array}$ & $\begin{array}{l}\text { Mean } \\
\text { adjusted } \\
\text { treatment } \\
\text { effects (\%) }\end{array}$ & $\begin{array}{l}\text { Statistical } \\
\text { significance }\end{array}$ \\
\hline Maine & 1975 & 4 & 1.07 & -1.81 & $\mathbf{- 1 . 3 5}$ & negative \\
New York & 1976 & 15 & 0.85 & 0.37 & $\mathbf{0 . 0 1}$ & insignificant \\
New Jersey & 1977 & 8 & 1.98 & 0.65 & $\mathbf{0 . 5 9}$ & insignificant \\
Virginia & 1978 & 27 & 4.14 & 0.16 & $\mathbf{0 . 6 4}$ & insignificant \\
Ohio & 1979 & 41 & 2.10 & 0.20 & $\mathbf{0 . 0 1}$ & insignificant \\
Connecticut & 1980 & 4 & 1.44 & -0.46 & $\mathbf{- 0 . 2 4}$ & negative \\
Alabama & 1981 & 27 & 2.00 & 0.20 & $\mathbf{0 . 4 0}$ & insignificant \\
Pennsylvania & 1982 & 6 & 1.77 & -1.94 & $\mathbf{- 0 . 7 0}$ & negative \\
Georgia & 1983 & 12 & 0.60 & -1.11 & $\mathbf{- 0 . 8 5}$ & negative \\
Massachusetts & 1984 & 3 & 2.32 & 0.54 & $\mathbf{0 . 3 2}$ & insignificant \\
Nebraska & 1985 & 11 & 0.88 & 0.38 & $\mathbf{0 . 2 3}$ & insignificant \\
Tennessee & 1985 & 25 & 1.65 & 1.52 & $\mathbf{1 . 3 1}$ & $1 \%$ \\
Mississippi & 1986 & 5 & 0.56 & -0.33 & $\mathbf{0 . 6 0}$ & insignificant \\
Kansas & 1987 & 11 & 1.15 & 0.07 & $\mathbf{- 0 . 0 9}$ & negative \\
Michigan & 1987 & 5 & 0.51 & 2.71 & $\mathbf{1 . 9 4}$ & $5 \%$ \\
North Dakota & 1987 & 6 & 2.82 & 0.34 & $\mathbf{0 . 6 1}$ & insignificant \\
West Virginia & 1987 & 4 & 0.41 & 0.88 & $\mathbf{0 . 7 6}$ & insignificant \\
Illinois & 1988 & 9 & 0.26 & 0.09 & $\mathbf{0 . 4 6}$ & insignificant \\
Louisiana & 1988 & 8 & 0.80 & 0.72 & $\mathbf{1 . 1 5}$ & $5 \%$ \\
Oklahoma & 1988 & 8 & 1.73 & 1.50 & $\mathbf{1 . 6 5}$ & $\begin{array}{c}\text { 1. } \\
\text { Texas }\end{array}$ \\
Missouri & 1988 & 2 & 0.75 & -0.90 & $\mathbf{- 1 . 0 5}$ & negative \\
Wisconsin & 1990 & 28 & 1.94 & 0.83 & $\mathbf{1 . 0 9}$ & $1 \%$ \\
\hline
\end{tabular}

Note: Each of the 23 events of bank branching deregulations is assessed separately to establish the statistical significance of its mean treatment effect. A different number of county-pairs is used in each deregulation event, determined by geography and the deregulation schedule of its neighboring states. The results of the assessments are presented in this table. The raw treatment effect is simply the difference-in-differences of average growth rate in the "pre-" and "post-" periods between the treatment counties and the control counties. Adjusted treatment effects control for change in income gap and growth opportunity gap between the "pre-" and "post-" periods, which if not adjusted for can bias the point estimate. The mean treatment effect is obtained by averaging the treatment effects of all county-pairs associated with a deregulation event. On average, evaluation of a deregulation event is based on 12 county-pairs. The critical values of mean treatment effects are empirically obtained through applying placebo deregulations to non-event borders. We use the critical values tabulated in Table 5, which already adjust for the downward bias created by positive spatial correlation of treatment effects within a chain of neighboring county-pairs. We assess the statistical significance of mean treatment effects only when they are positive. 


\subsection{Establishing statistical significance}

Furthermore, comparing the values of the point estimates to the critical values at various confidence levels, obtained from the fictitious placebo deregulation events, clearly indicates that most of the positive treatment effects are not statistically distinguished from what can be obtained in fictitious treatments.

The evaluation results of statistical significance are also indicated in Table 7. Out of the 23 actual events of branching deregulations, in seven of them the mean treatment effects are negative. Therefore, they are immediately excluded from further examination. In the remaining 16 events, the point estimates are at least positive. We compare them against the two tables of critical values: one (Table 4) ignores spatial dependence within a chain of neighboring county-pairs and is biased downward, whereas the other (Table 5) adjusts for it. Using the data from the table that assumes no spatial dependence, which underestimates the standard errors, there are only seven events where we can establish statistical significance at higher than $90 \%$ level. After adjusting for downward-biased standard errors due to positive spatial correlations, only five are left that are statistically significant at $90 \%$ (or higher) confidence level. These five states are (in alphabetical order): Louisiana $(8,1.15 \%,>95 \%)$, Michigan $(5,1.95 \%,>95 \%)$, Missouri $(28,1.09 \%$, $>99 \%)$, Oklahoma $(8,1.65 \%,>99 \%)$, and Tennessee $(25,1.31 \%,>99 \%)$. Numbers in the parentheses are, respectively, number of county-pairs used to calculate the mean treatment effect, point estimate of the treatment effect, and statistical confidence level.

Based on the methodology of this study, we can establish that in these five states, growth accelerations indeed occurred in the years surrounding the deregulation events. These five growth accelerations are economically quite sizable considering that the 
average (unconditional) annual growth rates in the "pre-" period is only about $1.7 \%$. This magnitude is nevertheless plausible in the several years immediately after deregulation because a small change in the value of stock of existing capital can have a large effect on economic output if the benefits are realized in a short period of time (Jayaratne and Strahan, 1996, p. 658). Nevertheless, these five cases are out of the 23 events examined. In the vast majority (18 cases, or $80 \%$ of the total) of the state-level branching deregulations we examine, significant economic growth accelerations are not able to be established in the years surrounding the deregulation events.

It is worth mentioning that all of the five growth accelerations took place after 1985 , in the later part of our sample period. Prior to that, there was no single case of significant growth accelerations and the average treatment effect is $-0.12 \%$. Year 1985 was the beginning of a period of dramatically increased bank failure rates, which drove small banks to drop their opposition to intra- and inter-state acquisitions to find higher purchase prices. Thus, these deregulations took place in totally different circumstances, were more unexpected, and could have been driven by different conditions than their predecessors. Another important difference of these five events from others is that the interstate banking deregulations in all five cases took place before or at the same year of the intrastate branching deregulations, and therefore, these branching deregulations may introduce stronger potential competitions than in other states, by also allowing out-ofstate (e.g., from New York) large competitors to participate. To sum up, there could be a structural break in 1985 on the nature and characteristic of the branching deregulations and on the relations between deregulation events and growth accelerations.

The main goal of this paper is to provide a generalized methodology and 
evaluation framework to assess the economic effect of many types of state-specific regulatory changes, and branching deregulation is but one example. Thus, we do not intend to explore very deeply to provide rigorous evidence to explain why we have found what we have found, although we will offer some plausible explanations later in Section 7.

So far we have established that, in 5 out of 23 cases, local economic growth appeared to significantly accelerate in the years surrounding the deregulation events, although it is a different question whether deregulations had caused them. In the other events, no significant correlation between deregulation events and growth accelerations can be statistically established. Hopefully, future research can go deeper into what we have found empirically. Before providing some of our explanations of the results, we will first spend some time in Section 6 to establish the robustness of the methodology used in this study.

\section{Robustness Check: Geographic Spillover of Deregulation Effects?}

If local residents can easily obtain access to credit from commercial banks on opposite sides of state borders, then the results of no deregulation effects can be easily explained by direct or indirect spillover of lending from the newly deregulated states to their neighbors across state borders. If border counties on both sides of the regulation change border benefit from the deregulation, then it is not surprising that we cannot find differences between them.

Cross-border lending by local commercial banks, however, should be minimal. In banking antitrust analysis done by Federal Reserve Banks, the local market outside 
metropolitan areas is usually defined as a single county. ${ }^{17}$ There are many reasons why banking markets are local, although the lending distance of nonbank financial institutions and credit-card-type lending in particular has been increasing over time.

First, information asymmetry increases in distance as a result of communication and transport costs (Degryse and Ongena, 2004). Petersen and Rajan (2002), and Kwast et al. (1997) both find that in the 1980s, when most of the branching deregulations took place, the median distance between banks and borrowers was 4 miles (and the $75^{\text {th }}$ percentile is 12 miles), which is well within county boundaries. Petersen and Rajan (2002) also find that $67 \%$ of the communications between banks and borrowers were done by face-to-face personal meeting. Garmaise and Moskowitz's (2004, 2006) data on commercial real estate loans also suggest localized lending with a maximum radius of 15 miles. Many believe that the recent adoption of credit scoring models could increase lending distance. However, using Community Reinvestment Act data, Brevoort and Hannan (2006) show that distance is if anything becoming more of an important factor even within a local market.

Second, state borders can create contract-enforcing barriers greater than those created by county borders. When defaults or disputes arise, in order for banks to recover loans from out-of-state debtors, they could incur substantial costs in the process of going through the court system in a different state because their own in-house legal specialists could not have accumulated sufficient experiences in the neighboring state's bankruptcy and foreclosure laws.

\footnotetext{
${ }^{17}$ The Fed's definition of local banking market is mainly based on the commuting pattern information obtained from the "Journey to Work" Census, assuming that if people do cross borders in a mass scale on a regular basis, then such borders do not effectively stop banks from competing to provide services to residents on the other side of the border, and the two counties should belong to the same local market. The definition is designed for anti-trust analysis, but it is also helpful in supporting the empirical design of this study.
} 
To sum up, even if borrowers are willing to take the great hassles to travel across state borders, bankers could find it costly to lend to them, for information asymmetry reasons. Nevertheless, there could be some sort of indirect spillover of lending across state borders that could invalidate the comparison made in this study. For instance, residents in the newly deregulated states could now have more disposable cash on hand, which could be lent to their friends or relatives on opposite sides of state borders.

To consider this possibility, we collect a second group of counties as an alternative control, and then perform the same difference-in-differences analysis. The members of the treatment group remain the same. We will now compare the deregulated (treated) counties not to their immediate neighbors, but to their paired hinterland counties (as defined in Section 2.3) on the opposite side of the border. The hinterland counties are located within the still-regulated states, but farther away from the state borders. In other words, now the counties in the treatment group and the control group are co-contiguous, with the border deregulated counties located in-between them (see Figure 2 for an example). The "Journey to Work" Census shows that although there still is a small number of people commuting between contiguous counties, the number is sharply reduced to trivial if the flow is between two co-contiguous (not directly contiguous) counties.

If there were spillovers of deregulation effects that affected our previous results, which use border counties as control, the use of hinterland counties as control should reduce such influence, and the same difference-in-differences tests should signal many more cases of significant growth accelerations. If there is any geographic spillover of 
lending across state borders, the hinterland counties that are farther away from state borders should not benefit as much, because spillovers should mainly benefit the border counties, if it is assumed that it takes lenders more efforts to do business with more distant borrowers, and that people have more friends in immediate adjacent counties. The empirical design, thus, does not rely on assumptions about particular types of crossborder spillovers.

The results of the robustness test using hinterland counties as a second control group are presented in Table 8 . The use of an alternative control group does not alter the main evaluation results. In only one more deregulation event (1986 in Mississippi) a statistically significant treatment effect is identified. In this event, using hinterland counties as a control group would signal growth acceleration marginally significant at $90 \%$ confidence level. Furthermore, the statistical significance levels of the original five growth acceleration cases are higher when border counties as opposed to hinterland counties are used as control group, which goes against the hypothesis that cross-border spillover of deregulation effects bias against finding significant deregulation effects. The results in general suggest that cross-border spillover of deregulation effects should not have first-order influence on our previous results. 


\section{Table 8: Evaluating the actual deregulation events using the hinterland counties as the control group}

\begin{tabular}{|c|c|c|c|c|c|c|}
\hline $\begin{array}{l}\text { Deregulation } \\
\text { state }\end{array}$ & $\begin{array}{l}\text { First year of } \\
\text { deregulation }\end{array}$ & $\begin{array}{l}\text { Number of } \\
\text { county- } \\
\text { pairs }\end{array}$ & $\begin{array}{l}\text { Mean average } \\
\text { growth rate in } \\
\text { "pre-" period } \\
(\%)\end{array}$ & $\begin{array}{l}\text { Mean raw } \\
\text { treatment } \\
\text { effect }(\%)\end{array}$ & $\begin{array}{l}\text { Mean } \\
\text { adjusted } \\
\text { treatment } \\
\text { effect }(\%)\end{array}$ & $\begin{array}{l}\text { Statistical } \\
\text { significance }\end{array}$ \\
\hline Maine & 1975 & 3 & 1.07 & -0.44 & -0.63 & negative \\
\hline New York & 1976 & 14 & 0.85 & 0.79 & 0.28 & insignificant \\
\hline New Jersey & 1977 & 6 & 1.98 & 0.17 & 0.41 & insignificant \\
\hline Virginia & 1978 & 16 & 4.14 & -0.09 & 0.29 & insignificant \\
\hline Ohio & 1979 & 35 & 2.10 & -0.05 & -0.26 & negative \\
\hline Connecticut & 1980 & 2 & 1.44 & -1.63 & -0.73 & negative \\
\hline Alabama & 1981 & 22 & 2.00 & 0.09 & 0.37 & insignificant \\
\hline Pennsylvania & 1982 & 2 & 1.77 & 0.59 & 1.16 & insignificant \\
\hline Georgia & 1983 & 12 & 0.60 & -0.44 & 0.18 & insignificant \\
\hline Massachusetts & 1984 & 3 & 2.32 & -0.33 & -0.06 & negative \\
\hline Nebraska & 1985 & 11 & 0.88 & 0.16 & -0.11 & negative \\
\hline Tennessee & 1985 & 25 & 1.65 & 0.86 & 0.77 & $10 \%$ \\
\hline Mississippi & 1986 & 5 & 0.56 & 1.28 & 1.55 & $5 \%$ \\
\hline Kansas & 1987 & 11 & 1.15 & 0.56 & 0.49 & insignificant \\
\hline Michigan & 1987 & 5 & 0.51 & 2.68 & 1.99 & $5 \%$ \\
\hline North Dakota & 1987 & 6 & 2.82 & -3.63 & -2.26 & negative \\
\hline West Virginia & 1987 & 4 & 0.41 & -0.24 & 0.20 & insignificant \\
\hline Illinois & 1988 & 9 & 0.26 & -0.80 & 0.11 & insignificant \\
\hline Louisiana & 1988 & 8 & 0.80 & 0.57 & 1.05 & $10 \%$ \\
\hline Oklahoma & 1988 & 8 & 1.73 & 0.51 & 1.27 & $5 \%$ \\
\hline Texas & 1988 & 2 & 0.75 & -1.65 & -1.33 & negative \\
\hline Missouri & 1990 & 24 & 1.94 & 0.66 & 1.06 & $1 \%$ \\
\hline Wisconsin & 1990 & 16 & 0.93 & 2.21 & 0.53 & insignificant \\
\hline
\end{tabular}

Note: Each of the 23 events of branching deregulation is assessed separately to establish the statistical significance of its mean treatment effect. A different number of county-pairs is used in each deregulation event, determined by geography and the deregulation schedule of its neighboring states. The results of the assessments are presented in this table. The raw treatment effect is simply the difference-in-differences of average growth rate in the "pre-" and "post-" periods between the treatment counties and the control counties (in this case, the second control group of "hinterland counties"). Adjusted treatment effects control for change in income gap and growth opportunity gap between "pre-" and "post-" periods, which if not adjusted for can bias the point estimate. The mean treatment effect is obtained by averaging the treatment effects of all county-pairs associated with a deregulation event. Evaluation of a deregulation event is based on 11 county-pairs on average. The critical values of mean treatment effects are empirically obtained through simulating placebo deregulations on non-event borders. We use the critical values tabulated in Table 5, which already adjust for the downward bias created by positive spatial correlation of treatment effects within a chain of neighboring county-pairs. We assess the statistical significance of treatment effects only when they are positive. 


\section{Discussions}

Did removal of restrictions on statewide branching create significant growth accelerations in deregulated U.S. states? Previous empirical literature has found that liberalization of statewide branching widely and significantly accelerated local economic growth. This study provides a more precise test by comparing border counties in deregulated states with their contiguous neighbors on opposite sides of state borders where intrastate branching was at first prohibited. The comparisons reveal that significant growth acceleration in the years surrounding the deregulation events is not a general phenomenon as suggested by Jayaratne and Strahan (1996). In only 5 out of 23 of the deregulation events examined, statistically significant growth acceleration can be firmly established at a $>90 \%$ confidence level.

The endogeneity problem could be one of the reasons why previous studies tend to find correlation between deregulation and growth accelerations. Kroszner and Strahan (1999), for instance, find that the relative strength of winners (large banks and small, bank-dependent firms) and losers (small banks and the rival insurance firms) of deregulation can explain the timing of branching deregulation across states. Also, when state-level economic growth is studied, it is possible that the correlation found is created by deregulations being induced by an expectation of growth opportunities that are not observed by econometricians. State-level deregulations occurred in waves, usually clustered by region, and correlations identified in existing literature could pick up regional growth trends. The advantage of studying county-level growth is that it is unlikely that economic conditions of a county had influenced regulatory decisions at state level made by state legislatures, which have to accommodate interests of all constituencies, not only the border counties. 
Moreover, Wheelock (2003) points out that states in the South and New England tended to deregulate earlier than Midwestern states, and several of these had among the highest average annual growth rates. It is possible that the growth accelerations are region-wide phenomena independent of banking regulations in individual states. When previous researchers compared earlier deregulated states in these regions with states in other regions, it is possible that they picked up the region-wide growth acceleration trend as evidence for the impact of banking deregulation at the state level. Our analysis at the lower geographic level is relatively free from the influence of such cross-region heterogeneity.

In financing economic growth, there could be a substitution effect between commercial banks (which were subject to branching regulation) and nonbank financial institutions (which have been free from such geographic restrictions). One explanation for the results of this study could be that local entrepreneurs are able to substitute other sources of financing (e.g., credit from nonbank financial institutions that lend at a longer distance) for bank financing. In the United States, long before the deregulations, nonbank financial institutions had developed gradually to meet the demands frustrated by geographically restricted commercial banks. In the long term, the financing constraints created by branching regulation became less binding as nonbank financial institutions and capital markets reduced firms' dependence on banks. The negative effect of bank regulation on the local economy could have been overstated by not taking into account these substitution effects. 
Furthermore, Kane (1996) and Kroszner and Strahan (1999) have pointed out the irony that the cost of regulation is usually the lowest at the time it is removed. In the history of the U.S. financial service industry, before an exclusionary statute comes to be formally rescinded, most of the effects targeted by the rescission will have already been tolerated by the enforcement system for years. Usually, statutory change does not occur until circumventive activity has driven the protective value of existing rules to their proponents below the amount opponents are willing to pay for their removal. Prior to the deregulations, the value of geographic exclusion had been eroded by technological innovations in lending. According to Petersen and Rajan (2002), lending distance of nonbank finance companies was growing rapidly in the 1970 s and $1980 \mathrm{~s} .{ }^{18}$ The increased ability of finance companies to lend to distant borrowers without setting up local branches clearly had made branching regulations less effective over time in protecting the rents of local banks, which could explain why branching deregulations, at the time they took place, usually had already lost relevance to the local economy.

In the short term, it was still possible that, in the past, regulations and geographic restrictions on banks' expansions had inflicted large costs on the U.S. economy, in particular at the early stage of industrialization, as the absence of big banks posed constraints on financial needs of growing industrial corporations ${ }^{19}$. In the long term, such constraints have been greatly relieved because the development of capital market and unregulated nonbank financial institutions has turned the U.S. economy into one that is

\footnotetext{
${ }^{18}$ The median lending distance of nonbanks increased from 15.5 miles in the 1970 s to 42 miles in the $1980 \mathrm{~s}$, and the share of in-person communication between borrowers and finance companies dropped from $27 \%$ to $12 \%$ among all types of communications, including phone-call and mail, whereas for banks, it just dropped from $77 \%$ to $67 \%$.

${ }^{19}$ Giedeman (2005) finds that, during 1911-1922, restrictions on branch banking cause the severity of external finance constraints to increase with firm size. Rousseau and Wachtel (2005) find that the positive relation between finance and growth exists only for economies at per capita income level between $\$ 3,000$ and $\$ 12,000$ (in 1995 constant USD), which may suggest that branching restrictions were more harmful in the past than now.
} 
less bank-dependent than its European counterparts. Furthermore, market players, to meet the frustrated demand and to exploit profit opportunities, have been constantly circumventing and eroding the burdensome regulations via legal loopholes, contractual and information-processing innovations, regulatory/structural arbitrage, and interpretive changes in statute-implementing regulations that regulatory bodies actually enforce (Kane [1981, 1984, 1996] has provided detailed analyses). As Kane (1981, p. 359) asserts, "In the 1970s, loophole mining and fabrication became the main business of modern depository institutions." The development of all of these substitutes, however, had taken up significant time, talents, and money. To sum up, in the past, banking regulation could have inflicted costs on the economy in the endless "arm race" in loophole-mining and re-regulation between market players and regulators. Despite its long-term irrelevance, branching restrictions in the U.S. could still be bad because it may have inflicted costs in the short term, which could mean several decades.

\section{Implications for European banking market integration}

The results of this paper based on US state-level deregulation experiences can also shed some light on the potential economic benefits of the ongoing banking market integration in Europe. Before the removal of restrictions on interstate banking, the United States actually had 50 separate banking systems (one for each state); before the removal of restrictions on statewide banking, each county within a state was actually a separate banking system. Therefore, for academic purpose we may draw analogy between the European Union and the United States; a European country and a US state; a sub- 
national region within a European country and a US county, to make an educated guess on the potential benefits of European banking market integration.

This study finds that the state-level deregulations in the US produced uneven results: large effects for some states, insignificant for many others, and negative for the rest. The study shows that the bank branching deregulations that took place before 1985 were in general not followed by faster economic growth. As a matter of fact, these earlier liberalizers grew on average $0.12 \%$ per year slower compared to their neighbors. However, it does not follow that our results have to be inconsistent with the Jayaratne and Strahan (1996) study, which finds positive effects on average. We need to look into the heterogeneity of the results to make a fair and comprehensive assessment. In contrast to the negative results of the earlier deregulation events, deregulations taking place after 1985 were in general associated with positive effects and there were five cases (Louisiana, Michigan, Missouri, Oklahoma, and Tennessee) in which the intra-state branching deregulations were followed by statistically significant growth accelerations. I noticed that in all of these five cases, inter-state banking deregulations took place before or at least at the same year of the intra-state branching deregulations. Therefore, in these cases the introduction of nationwide potential acquirers (mainly from New York and North Carolina) created greater competitive pressures than did most (nine out of ten, the exception being Massachusetts in 1984) of the statewide branching deregulations before 1985 that did not open the markets to only in-state or regional competitors.

The US experiences have implications for the banking market integration in Europe because we can compare European countries to the US states, and the regions 
within a European country to the US counties ${ }^{20}$. The results of this study would suggest that removing barriers that fragment the national banking market within a European country can produce greater benefit for the national economy if foreign investors and banks are not discriminated to own and control domestic banks. In a domestic banking market that is fragmented before the removal of domestic barriers, most domestic banks are likely to be small, and few national champions exist to actively acquire small players and rapidly consolidate the market after the removal of legal barriers. Mergers among small or equal size partners are likely to be followed by more difficult (corporate) cultural and organizational integration between the two partners and the realization of revenue and cost synergy. The results of this study would suggest that: (1) in Europe the involvement of (large) foreign banks can help better exploit the opportunities made available by the removal of within-country legal barriers; (2) the fostering of national champions through the removal of domestic barriers can make the domestic banking sector more competitive in the pan-European market, as can be evident by the successes of New York and North Carolina banks in US national banking in the post-Riegle-Neal era (since the late 1990s). The early integration of statewide banking market in these two states had allowed state-level banking champions to emerge and to develop earlier than their counterparts in other states in experiences and capacity of taking over out-of-state markets when it becomes possible after the removal of inter-state legal barriers.

\footnotetext{
${ }^{20}$ We believe this comparison is realistic. Forni and Reichlin (1997) decompose output fluctuations of the European Union (within-country) regions into Europe-wide, national, and regional components, and output fluctuations of U.S. counties into national, state, and county-specific components. They find that variance composition is similar, with Europe-wide or U.S. national components explaining nearly half of the variance, and region or county-specific components explaining more than (European) national or (US) state-specific components.
} 
This study finds that the removal of statewide branching restrictions had uneven effects on different states. The effect of a specific deregulation depends on where and when it takes place; and the actual level of competition already existing in the local markets before the removal of legal barriers. From the results I have noticed that the local (county-level) banking markets that were previously more competitive usually benefited less from the deregulations. In previously more concentrated (competitive) local markets, deregulations were in general associated with larger (smaller) effects. A similar difference is found in the comparison of rural versus urban banking markets. The reason is quite intuitive: if a local market is already quite competitive although the competition arises solely from the locals; then the exclusion of competition from outside the county is unlikely to be a binding constraint for the local economy and borrowers, and the removal of the barriers is unlikely to create much extra benefit either. This is true for most urban markets (such as New York and Los Angles) in the US, because in these places local competitors are already sufficient for the market to be very contestable.

In Europe, domestic banking markets are more competitive in some countries (regions) than in others. The strengthening of nationwide or Europe-wide competition thus could generate uneven benefits across countries and regions: some may benefit more than do others. In Germany and Italy for example, domestic markets are fragmented for historical and institutional reasons because local savings banks do not compete against each other in the same local markets. In such markets, if the domestic barriers against inter-market competition are removed, then the addition of outside competition could contribute significantly to higher level of competition. However, such extra benefits could be smaller for metropolitan areas such as London or Paris. In large cities, the 
greater market size allows large number of strong competitors to co-exist; and the local markets are typically over-banked already. In such cases, further entry by outsiders may not have a significant impact on bank market competition, because the local players have already created fierce competition among themselves, as are the cases also in the Dutch market (Claessens and Laeven, 2004).

European Union as a whole is comparable to the United States in terms of population, economy size, and the level of economic and financial development. Across regions within the United States the institutional environment such as the legal system is more homogenous, compared with across countries within the European Union. With the absence of cultural and language barriers within the United States, the economic benefits we have observed from the US deregulation experiences are likely to be an upper bound estimate of the potential economic benefits of the European banking market integration. Nevertheless, it is still possible that the banking market integration in Europe could produce greater benefits than in the US.

First, the costs of geographic restrictions in the US could have been higher had nonbank financial institutions been underdeveloped (and thus, could not effectively substitute for the role of commercial banks when they were restricted), or had corporations had relatively limited cross-border access to nonbank financial institutions or the capital markets. This situation happens to be the case in Europe, as European capital markets are both underdeveloped and fragmented relative to in the US (Hartmann, Maddaloni, and Manganelli, 2003).

Second, this study finds that the deregulations taking place in the later half of the sample generated greater economic benefit than did the earlier deregulations. This is 
consistent with DeLong and DeYoung (2007)'s results that there exists so-called "learning-by-observing" in the banking sector consolidation process so that the earlier M\&As were typically less successful than the later ones. European banks, if they can learn by observing the US experiences, could more efficiently exploit the new competitive environment enabled by the removal of within-Europe barriers. For these reasons explained above, it is still possible that the strengthening of Europe's banking market integration will create faster, greater, and wider benefits for the European economy.

This study also provides important lessons for future research projects related to the economic effects of European banking market integration. The evaluations done in this study show that the deregulation effects could be uneven, and the "average effect" typically ignores important information. I believe that an always necessary exercise in this type of policy evaluations is to look into the heterogeneity of the evaluation results and study why some countries or regions benefit more (or less) from a certain policy change, and whether some sectors, segments (e.g., firm-size groups) of the economy or population benefit more than do others. Such analyses can provide richer details than do the "average effect" results. Such information can help shed light on many competing hypotheses regarding how a certain economic policy matters, and in this case, the real effects of bank competition. Looking into these details can greatly enhanced the information set of the policy-makers, because the economic effects of many policies are distributional and cannot be revealed by observing the average effects alone. 


\section{References}

Amel, Dean, 1993, "State laws affecting the geographic expansion of commercial banks," unpublished manuscript (an updated version covering more recent years is obtained directly from the author), Board of Governors of Federal Reserve System

Ashcraft, Adam B., 2006, "New evidence on the lending channel," Journal of Money, Credit, and Banking, Vol.38(3): 751-775

Ashcraft, Adam B., 2005, "Are banks really special? New evidence from the FDIC-induced failure of healthy banks," The American Economic Review, Vol. 95(5): 1712-30.

Ashcraft, Adam B., and Murillo Campello, 2003, "Firm balance sheets and monetary policy transmission," Journal of Monetary Economics, forthcoming.

Barro, Robert J., and Xavier Sala-i-Martin, 1992, "Convergence," Journal of Political Economy, Vol.100(2): 223-51.

Berger, Allen N, Rebecca S. Demsetz, and Philip E. Strahan, 1999, "The Consolidation of the Financial Services Industry: Causes, Consequences, and Implications for the Future," Journal of Banking and Finance, Vol. 23(2-4): 135-94.

Berger, Allen N., Anil K. Kashyap, and Joseph M. Scalise, 1995, "The transformation of the U.S. banking industry: What a long, strange trip it's been," Brookings Papers on Economic Activity, Vol.2: 55-218

Berger, Allen N., Nathan H. Miller, Mitchell A. Petersen, Raghuram G. Rajan, Jeremy C. Stein, 2005, "Does function follow organizational form? Evidence from the lending practices of large and small banks," Journal of Financial Economics, Vol. 76 (2): 237-269.

Bertrand, Marianne, Esther Duflo, and Sendhil Mullainathan, 2004, "How Much Should We Trust Differences-in-Differences Estimates?" The Quarterly Journal of Economics, Vol. 119(1): 249-275.

Black, Sandra E., 1999, "Do better schools matter? Parental valuation of elementary education," The Quarterly Journal of Economics, Vol. 114 (2): 577-599.

Black, Sandra E., and Philip E. Strahan, 2002, "Entrepreneurship and bank credit availability," Journal of Finance, Vol. 57 (6): 2807-2833.

Brevoort, Kenneth P., and Timothy H. Hannan, 2006, "Commercial lending and distance: Evidence from community reinvestment act data," Journal of Money, Credit, and Banking, Vol.38(8): 1991-2012

Brickley, James A., James S. Linck, and Clifford W. Smith Jr., 2003, "Boundaries of firm: Evidence from the banking industry," Journal of Financial Economics, Vol.70(3): 351-383.

Calomiris, Charles W., and Joseph R. Mason, 2003, "Consequences of U.S. Bank Distress During the Depression," American Economic Review, Vol.93(3): 937-47. 
Card, David, and Kruger, Alan B., 1994, "Minimum wages and employment: A case study of the fast-food industry in New Jersey and Pennsylvania," American Economic Review, Vol. 84(4): 772-793.

Claessens, Stijn, and Luc Laeven, 2004, "What drives bank competition? Some international evidence," Journal of Money, Credit, and Banking, Vol.36(3): 563-63

Clair, Robert T., Jr. Gerald P. O’Driscoll, Kevin J. Yeats., 1994, "Is banking different? A reexamination of the case for regulation," CATO Journal, Vol. 13(3): 345-58.

Degryse, Hans, and Steven Ongena, 2004, "The impact of technology and regulation on the geographical scope of banking," Oxford Review of Economic Policy, Vol.20(4): 571-590

DeLong, Gayle, and Robert DeYoung, 2007, "Learning by observing: information spillovers in the execution and valuation of commercial bank M\&As," The Journal of Finance, Vol.62(1): 181-216

DiSalvo, James V., 1999, "Federal reserve geographic banking market definitions," Unpublished paper, Federal Reserve Bank of Philadelphia

Driscoll, John C., 2004, "Does bank lending affect output? Evidence from the U.S. states," Journal of Monetary Economics, Vol. 51 (3): 451-471.

Fox, William F., 1986, "Tax structure and the location of economic activity along state borders," National Tax Journal, Vol. 39: 387-401.

Freeman, Donald G., 2002, "Did state branching deregulation produce large growth effects?", Economic Letters, Vol.75: 383-389.

Garmaise, Mark J., and Tobias J. Moskowitz, 2004, "Confronting Information Asymmetries: Evidence from Real Estate Markets," Review of Financial Studies, Vol.17(2): 405-437.

Garmaise, Mark J., and Tobias J. Moskowitz, 2006, "Bank mergers and crime: The real and social effects of credit market competition," Journal of Finance, Vol.61(2): 495-538.

Garrett, Thomas A., Gary A. Wagner, and David C. Wheelock, 2004, "A spatial analysis of state banking regulation," Working Paper, Federal Reserve Bank of St. Louis.

Giedeman, Daniel C., 2005, "Branching banking restrictions and finance constraints in earlytwenty-century America," Journal of Economic History, Vol.65(1): 129-151

Gilbert, R. Alton, and Levis A. Kochin, 1989, “Local economic effects of bank failures.” Journal of Financial Services Research, Vol.3(4): 333-45.

Hartmann, Philipp, Angela Maddaloni, and Simone Manganelli, 2003, "The Euro area financial system: structure, integration and policy initiatives," Oxford Review of Economic Policy, Vol.19(1): 180-213

Holmes, Thomas J., 1998, "The effect of state policies on the location of manufacturing: Evidence from state borders," Journal of Political Economy, Vol. 106 (4): 667-705. 
Jayaratne, Jith, and Philip E. Strahan, 1996, "The finance-growth nexus: Evidence from bank branch deregulation," Quarterly Journal of Economics, Vol. 111 (3): 639-670.

Jayaratne, Jith, and Philip E. Strahan, 1997, "The benefits of branching deregulation," FRBNY Economic Policy Review, December Issue: 13-29.

Kane, Edward J., 1981, "Accelerating inflation, technological innovation, and the decreasing effectiveness of banking regulation," Journal of Finance, Vol.36(2): 355-367.

Kane, Edward J., 1984, "Technological and regulatory forces in the developing fusion of financial-services competition," Journal of Finance, Vol.39(3): 759-772.

Kane, Edward J., 1996, "De Jure interstate banking: Why only now?" Journal of Money, Credit and Banking, Vol.28(2): 141-161.

Kroszner, Randall S., and Philip E. Strahan, 1999, "What Drives Deregulation? Economics and Politics of the Relaxation of Bank Branching Restrictions," The Quarterly Journal of Economics, Vol. 114(4): 1437-1467.

Kwast, Myron L., Martha Starr-McCluer, and John D. Wolken, 1997, "Market Definition and the Analysis of Antitrust in Banking," Antitrust Bulletin, Vol.42: 973-95.

Levine, Ross, 2004, "Finance and growth: Theory and evidence" in Philippe Aghion and Steven Durlauf, eds., Handbook of Economic Growth, The Netherlands: Elsevier Science

Marquis, Milton, 2001, "What's Different about Banks--Still?”, FRBSF Economic Letter, 200109.

Petersen, Mitchell, and Raghuram G. Rajan, 2002, "Does distance still matter? The revolution in small business lending," Journal of Finance, Vol. 57 (6): 2533-2570.

Prager, Robin A., and Timothy Hannan, 1998, "Do Substantial Horizontal Mergers Generate Significant Price Effects? Evidence from the Banking Industry," Journal of Industrial Economics, Vol.46: 433-52.

Rhoades, Stephen, 2000, "Bank Mergers and Banking Structure in the U.S., 1980-1998," Board of Governors Staff Study 174, Federal Reserve System.

Rousseau, Peter, and Paul Wachtel, 2005, "Economic Growth and Financial Depth: Is the relationship extinct already?" Presented at the UNU/WIDER conference on Financial Sector Development for Growth and Poverty Reduction.

Strahan, Philip E., 2003, "The real effects of U.S. banking deregulation," The Federal Reserve Bank of St. Louis Review, Vol.85(4):111-128.

Wall, Howard J., 2004, "Entrepreneurship and the deregulation of banking," Economic Letters, Vol. 82: 333-339.

Wheelock, David C., 2003, "Commentary on Philip E. Strahan, 'The real effects of U.S. banking deregulation," Federal Reserve Bank of St. Louis Review Vol. 85(4): 129-133. 


\section{Appendix: Contiguous Counties across regulation change borders}

Note: The table lists the names of treatment states/counties that deregulated bank branching earlier than their neighbors, and their paired control states/counties, which remained regulated for a longer period of time. The first control group includes border contiguous counties in the regulated states, whereas the second control group includes "hinterland counties" farther away from the state borders. The treatment effects estimated based on the difference-in-differences growth rates between the treatment counties and their paired contiguous counties are reported. The adjusted treatment effects correct the bias created by income gap and growth opportunity gap between the treatment and control groups, using the formula specified in Eq.(6) .

\begin{tabular}{|c|c|c|c|c|c|c|}
\hline $\begin{array}{l}\text { Treatment } \\
\text { state }\end{array}$ & $\begin{array}{l}\text { Treatment } \\
\text { county }\end{array}$ & Control state & $\begin{array}{l}\text { Contiguous } \\
\text { county }\end{array}$ & $\begin{array}{l}\text { Hinterland } \\
\text { county }\end{array}$ & $\begin{array}{l}\text { Raw } \\
\text { treatment } \\
\text { effect } \\
(\%) \\
\end{array}$ & $\begin{array}{l}\text { Adjusted } \\
\text { treatment } \\
\text { effect } \\
(\%) \\
\%(\%)\end{array}$ \\
\hline Maine & Oxford & New Hampshire & Coos & & -0.3 & -0.7 \\
\hline Maine & Oxford & New Hampshire & Carroll & Belknap & -3.7 & -3.1 \\
\hline Maine & York & New Hampshire & Carroll & Belknap & -1.2 & -1.2 \\
\hline Maine & York & New Hampshire & Strafford & Merimack & -2.1 & -0.4 \\
\hline New York & Dutchess & Connecticut & Litchfield & Hartford & -1.0 & -0.7 \\
\hline New York & Putnam & Connecticut & Fairfield & New Haven & 0.7 & 0.9 \\
\hline New York & Westchester & Connecticut & Fairfield & New Haven & -0.7 & -0.7 \\
\hline New York & Rensselaer & Massachusetts & Berkshire & Hampshire & 0.1 & 0.1 \\
\hline New York & Columbia & Massachusetts & Berkshire & Hampshire & -1.3 & -0.3 \\
\hline New York & Chautauqua & Pennsylvania & Erie & Crawford & 1.5 & 0.7 \\
\hline New York & Chautauqua & Pennsylvania & Warren & Forest & 1.9 & 1.0 \\
\hline New York & Cattaraugus & Pennsylvania & McKean & Elk & 0.4 & 0.2 \\
\hline New York & Allegany & Pennsylvania & Potter & Clinton & 0.0 & -0.3 \\
\hline New York & Steuben & Pennsylvania & Tioga & Lycoming & 1.2 & 0.0 \\
\hline New York & Chemung & Pennsylvania & Bradford & Sullivan & -0.5 & -0.6 \\
\hline New York & Tioga & Pennsylvania & Bradford & Wyoming & 1.0 & 0.5 \\
\hline New York & Broome & Pennsylvania & Susquehanna & Wyoming & -0.5 & -0.3 \\
\hline New York & Delaware & Pennsylvania & Wayne & Lackawanna & 1.9 & -0.1 \\
\hline New York & Sullivan & Pennsylvania & Pike & & 1.1 & -0.2 \\
\hline New Jersey & Sussex & Pennsylvania & Pike & & 1.2 & 0.4 \\
\hline New Jersey & Warren & Pennsylvania & Monroe & Lackawanna & 0.3 & 1.1 \\
\hline New Jersey & Warren & Pennsylvania & Northampton & Lehigh & 0.6 & 0.6 \\
\hline New Jersey & Hunterdon & Pennsylvania & Bucks & Montgomery & 1.8 & 1.5 \\
\hline New Jersey & Mercer & Pennsylvania & Bucks & Montgomery & 0.4 & 0.5 \\
\hline New Jersey & Burlington & Pennsylvania & Bucks & Lehigh & 1.9 & 1.2 \\
\hline New Jersey & Camden & Pennsylvania & Philadelphia & Montgomery & 1.1 & 0.8 \\
\hline New Jersey & Gloucester & Pennsylvania & Delaware & & -2.1 & -1.4 \\
\hline Virginia & Buchanan & Kentucky & Pike & Martin & -0.7 & -0.3 \\
\hline Virginia & Dickinson & Kentucky & Pike & Floyd & -4.5 & -2.4 \\
\hline Virginia & Wise & Kentucky & Letcher & Knott & -4.2 & -0.6 \\
\hline Virginia & Lee & Kentucky & Harlan & Leslie & 0.0 & 1.4 \\
\hline Virginia & Lee & Kentucky & Bell & Knox & -1.6 & 0.7 \\
\hline Virginia & Lee & Tennessee & Claiborne & Union & 0.4 & 1.1 \\
\hline Virginia & Lee & Tennessee & Hancock & Grainger & -4.2 & 0.1 \\
\hline Virginia & Scott & Tennessee & Hawkins & & 0.5 & 0.5 \\
\hline Virginia & Scott & Tennessee & Sullivan & Washington & -0.5 & 0.2 \\
\hline
\end{tabular}




\begin{tabular}{|c|c|c|c|c|c|c|}
\hline Virginia & Washington & Tennessee & Sullivan & & -0.7 & 0.4 \\
\hline Virginia & Washington & Tennessee & Johnson & & 2.0 & 1.3 \\
\hline Virginia & Loudoun & West Virginia & Jefferson & & 0.7 & 0.7 \\
\hline Virginia & Clarke & West Virginia & Jefferson & & -3.6 & -1.3 \\
\hline Virginia & Frederick & West Virginia & Berkeley & & 1.5 & 1.3 \\
\hline Virginia & Frederick & West Virginia & Morgan & & 3.6 & 1.3 \\
\hline Virginia & Frederick & West Virginia & Hampshire & & 2.7 & 0.8 \\
\hline Virginia & Shenandoah & West Virginia & Hardy & & 0.6 & 0.3 \\
\hline Virginia & Rockingham & West Virginia & Pendleton & Randolph & 2.8 & 0.5 \\
\hline Virginia & Highland & West Virginia & Pocahontas & Randolph & 0.1 & 0.7 \\
\hline Virginia & Bath & West Virginia & Pocahontas & Webster & -0.7 & 0.4 \\
\hline Virginia & Alleghany & West Virginia & Greenbrier & Nicholas & 3.7 & 1.7 \\
\hline Virginia & Craig & West Virginia & Monroe & & -0.3 & 0.3 \\
\hline Virginia & Giles & West Virginia & Monroe & & 0.6 & 0.5 \\
\hline Virginia & Giles & West Virginia & Mercer & Summers & 3.6 & 1.6 \\
\hline Virginia & Bland & West Virginia & Mercer & Raleigh & 2.3 & 1.9 \\
\hline Virginia & Tazewell & West Virginia & McDowell & Wyoming & 2.1 & 2.3 \\
\hline Virginia & Buchanan & West Virginia & McDowell & Mingo & -1.9 & 1.6 \\
\hline Ohio & Williams & Indiana & Steuben & LaGrange & -0.7 & -1.0 \\
\hline Ohio & Defiance & Indiana & De Kalb & Noble & 0.7 & 0.3 \\
\hline Ohio & Paulding & Indiana & Allen & Whitley & -1.4 & -0.9 \\
\hline Ohio & Van Wert & Indiana & Adams & Wells & -1.7 & -0.8 \\
\hline Ohio & Mercer & Indiana & Jay & Blackford & -0.6 & 0.6 \\
\hline Ohio & Darke & Indiana & Randolph & Delaware & -0.7 & 0.0 \\
\hline Ohio & Preble & Indiana & Wayne & Henry & -1.5 & -0.5 \\
\hline Ohio & Preble & Indiana & Union & Fayette & -0.9 & 1.1 \\
\hline Ohio & Butler & Indiana & Franklin & Decatur & 0.4 & 0.2 \\
\hline Ohio & Hamilton & Indiana & Dearborn & Ripley & 0.9 & 0.5 \\
\hline Ohio & Hamilton & Kentucky & Boone & Gallatin & 1.5 & 0.6 \\
\hline Ohio & Hamilton & Kentucky & Kenton & Grant & 0.7 & 0.4 \\
\hline Ohio & Hamilton & Kentucky & Campbell & Pendleton & 1.2 & 0.7 \\
\hline Ohio & Clermont & Kentucky & Campbell & Pendleton & -0.2 & 0.0 \\
\hline Ohio & Clermont & Kentucky & Bracken & Robertson & -1.3 & -0.7 \\
\hline Ohio & Brown & Kentucky & Mason & Fleming & -0.8 & 0.0 \\
\hline Ohio & Adams & Kentucky & Lewis & Rowan & 2.4 & 1.2 \\
\hline Ohio & Scioto & Kentucky & Greenup & Carter & 3.0 & -1.1 \\
\hline Ohio & Lawrence & Kentucky & Boyd & Lawrence & 1.4 & -0.1 \\
\hline Ohio & Williams & Michigan & Hillsdale & Jackson & 0.8 & 0.4 \\
\hline Ohio & Fulton & Michigan & Lenawee & Washtenaw & 0.8 & 0.2 \\
\hline Ohio & Lucas & Michigan & Monroe & Wayne & -0.2 & -0.1 \\
\hline Ohio & Ashtabula & Pennsylvania & Erie & & -0.4 & -0.6 \\
\hline Ohio & Ashtabula & Pennsylvania & Crawford & & 0.6 & 1.0 \\
\hline Ohio & Trumbull & Pennsylvania & Mercer & Venango & -1.3 & -1.2 \\
\hline Ohio & Mahoning & Pennsylvania & Lawrence & Butler & -0.3 & -0.1 \\
\hline Ohio & Columbiana & Pennsylvania & Beaver & Allegheny & 0.4 & -1.5 \\
\hline Ohio & Lawrence & West Virginia & Wayne & Mingo & 0.5 & -0.2 \\
\hline Ohio & Lawrence & West Virginia & Cabell & Lincoln & -0.3 & -0.5 \\
\hline Ohio & Gallia & West Virginia & Mason & Putnam & 0.5 & 1.2 \\
\hline Ohio & Meigs & West Virginia & Mason & Putnam & 0.9 & 0.8 \\
\hline Ohio & Meigs & West Virginia & Jackson & Roane & 2.1 & 0.7 \\
\hline
\end{tabular}




\begin{tabular}{|c|c|c|c|c|c|c|}
\hline Ohio & Athens & West Virginia & Wood & Wirt & 0.7 & -0.5 \\
\hline Ohio & Washington & West Virginia & Wood & Wirt & 0.3 & -0.1 \\
\hline Ohio & Washington & West Virginia & Pleasants & Ritchie & 2.3 & 0.3 \\
\hline Ohio & Monroe & West Virginia & Tyler & Doddridge & -0.3 & 0.4 \\
\hline Ohio & Monroe & West Virginia & Wetzel & Harrison & -2.2 & -0.5 \\
\hline Ohio & Belmont & West Virginia & Marshall & & 1.0 & 0.3 \\
\hline Ohio & Belmont & West Virginia & Ohio & & -1.8 & -0.9 \\
\hline Ohio & Jefferson & West Virginia & Brooke & & 0.0 & 0.1 \\
\hline Ohio & Jefferson & West Virginia & Hancock & & 1.6 & 0.6 \\
\hline Connecticut & Litchfield & Massachusetts & Berkshire & & -1.9 & -0.7 \\
\hline Connecticut & Hartford & Massachusetts & Hampden & Hampshire & -0.1 & 0.0 \\
\hline Connecticut & Tolland & Massachusetts & Hampden & Hampshire & -1.0 & -0.5 \\
\hline Connecticut & Windham & Massachusetts & Worcester & & 1.1 & 0.2 \\
\hline Alabama & Baldwin & Florida & Escambia & & -1.3 & 0.4 \\
\hline Alabama & Escambia & Florida & Escambia & & -1.2 & 0.0 \\
\hline Alabama & Escambia & Florida & Santa Rosa & & -1.7 & -0.5 \\
\hline Alabama & Covington & Florida & Okaloosa & & -2.1 & -1.4 \\
\hline Alabama & Covington & Florida & Walton & & -0.7 & -0.4 \\
\hline Alabama & Geneva & Florida & Holmes & Washington & -1.3 & -1.1 \\
\hline Alabama & Houston & Florida & Jackson & Calhoun & -1.4 & -0.4 \\
\hline Alabama & Lauderdate & Mississippi & Tishomingo & Alcorn & 5.4 & 4.0 \\
\hline Alabama & Colbert & Mississippi & Tishomingo & Prentiss & 4.2 & 3.3 \\
\hline Alabama & Franklin & Mississippi & Itawamba & Lee & -7.2 & -3.1 \\
\hline Alabama & Marion & Mississippi & Itawamba & Lee & -1.7 & -0.8 \\
\hline Alabama & Lamar & Mississippi & Monroe & Chicksaw & 0.4 & 2.3 \\
\hline Alabama & Pickens & Mississippi & Lowndes & Oktibbeha & 2.4 & 0.9 \\
\hline Alabama & Pickens & Mississippi & Noxubee & Winston & 2.1 & 1.2 \\
\hline Alabama & Sumter & Mississippi & Kemper & Neshoba & -0.3 & -2.0 \\
\hline Alabama & Sumter & Mississippi & Lauderdale & Newton & -0.8 & -0.3 \\
\hline Alabama & Choctaw & Mississippi & Clarke & Jasper & 4.9 & 4.5 \\
\hline Alabama & Washington & Mississippi & Wayne & Jones & 2.4 & 1.8 \\
\hline Alabama & Washington & Mississippi & Greene & Perry & 1.8 & 3.4 \\
\hline Alabama & Mobile & Mississippi & George & Stone & 0.0 & 1.0 \\
\hline Alabama & Mobile & Mississippi & Jackson & Harrison & -0.8 & -0.3 \\
\hline Alabama & Lauderdale & Tennessee & Wayne & Perry & -0.1 & -0.7 \\
\hline Alabama & Lauderdale & Tennessee & Lawrence & Lewis & -0.2 & -1.4 \\
\hline Alabama & Limstone & Tennessee & Giles & Maury & 2.2 & 1.9 \\
\hline Alabama & Madison & Tennessee & Lincoln & Marshall & 2.8 & 1.6 \\
\hline Alabama & Jackson & Tennessee & Franklin & Coffee & -2.4 & -2.0 \\
\hline Alabama & Jackson & Tennessee & Marion & Grundy & 0.2 & -1.5 \\
\hline Pennsylvania & Beaver & West Virginia & Hancock & & -3.2 & -1.0 \\
\hline Pennsylvania & Washington & West Virginia & Brooke & & -0.9 & 0.7 \\
\hline Pennsylvania & Washington & West Virginia & Ohio & & -1.2 & -0.3 \\
\hline Pennsylvania & Greene & West Virginia & Marshall & & -0.7 & 0.0 \\
\hline Pennsylvania & Greene & West Virginia & Monongalia & Marion & -3.2 & -1.8 \\
\hline Pennsylvania & Fayette & West Virginia & Preston & Barbour & -2.3 & -1.7 \\
\hline Georgia & Seminole & Florida & Jackson & Washington & -1.8 & -1.6 \\
\hline Georgia & Decatur & Florida & Gadsden & Liberty & -0.4 & -0.1 \\
\hline Georgia & Grady & Florida & Leon & Wakulla & 0.6 & -0.3 \\
\hline Georgia & Thomas & Florida & Jeferson & Taylor & 0.0 & 0.1 \\
\hline
\end{tabular}




\begin{tabular}{|c|c|c|c|c|c|c|}
\hline Georgia & Brooks & Florida & Madison & Taylor & 4.7 & 1.9 \\
\hline Georgia & Lowndes & Florida & Madison & Lafayette & -1.0 & 0.7 \\
\hline Georgia & Echols & Florida & Hamilton & Suwannee & 0.3 & -1.5 \\
\hline Georgia & Clinch & Florida & Columbia & Gilchrist & -2.1 & -0.9 \\
\hline Georgia & Ware & Florida & Baker & Union & -3.5 & -2.9 \\
\hline Georgia & Charlton & Florida & Baker & Bradford & -5.1 & -2.5 \\
\hline Georgia & Charlton & Florida & Nassau & Duval & -3.4 & -2.6 \\
\hline Georgia & Camden & Florida & Nassau & Duval & -1.6 & -0.5 \\
\hline Massachusetts & Worcester & New Hampshire & Cheshire & Sullivan & -0.3 & 0.8 \\
\hline Massachusetts & Middlesex & New Hampshire & Hillsborough & Merrimack & 1.6 & 0.4 \\
\hline Massachusetts & Essex & New Hampshire & Rockingham & Strafford & 0.3 & -0.3 \\
\hline Nebraska & Dakota & Iowa & Woodbury & Ida & 0.7 & 0.0 \\
\hline Nebraska & Thurston & Iowa & Monona & Crawford & 1.2 & 0.6 \\
\hline Nebraska & Burt & Iowa & Monona & Crawford & -1.7 & -1.0 \\
\hline Nebraska & Burt & Iowa & Harrison & Shelby & 0.0 & -1.0 \\
\hline Nebraska & Washington & Iowa & Harrison & Shelby & -1.2 & -0.1 \\
\hline Nebraska & Douglas & Iowa & Pottawatamie & Cass & 0.3 & 0.9 \\
\hline Nebraska & Sarpy & Iowa & Mills & Montgomery & -1.1 & 0.5 \\
\hline Nebraska & Cass & Iowa & Mills & Montgomery & -1.1 & -0.2 \\
\hline Nebraska & Otoe & Iowa & Fremont & Page & 1.6 & 0.6 \\
\hline Nebraska & Nernaha & Missouri & Atchison & Nodaway & 1.8 & 1.4 \\
\hline Nebraska & Richardson & Missouri & Holt & Nodaway & 3.6 & 0.8 \\
\hline Tennessee & Lauderdate & Arkansas & Mississippi & Craighead & -2.3 & -0.2 \\
\hline Tennessee & Tipton & Arkansas & Mississippi & Poinsett & -0.7 & 0.7 \\
\hline Tennessee & Shelby & Arkansas & Crittenden & Cross & 0.4 & 0.6 \\
\hline Tennessee & Lake & Kentucky & Fulton & Hickman & 7.5 & 3.7 \\
\hline Tennessee & Obion & Kentucky & Fulton & Hickman & 3.0 & 3.5 \\
\hline Tennessee & Weakley & Kentucky & Graves & McCracken & 1.6 & 1.3 \\
\hline Tennessee & Henry & Kentucky & Calloway & Marshall & 0.6 & -0.4 \\
\hline Tennessee & Stwewart & Kentucky & Trigg & Lyon & 1.6 & 1.4 \\
\hline Tennessee & Montgomery & Kentucky & Christian & Hopkins & 1.8 & 1.2 \\
\hline Tennessee & Montgomery & Kentucky & Todd & Muhlenberg & -1.1 & -1.7 \\
\hline Tennessee & Robertson & Kentucky & Logan & Butler & 0.8 & 0.9 \\
\hline Tennessee & Robertson & Kentucky & Simpson & Warren & 0.0 & 0.7 \\
\hline Tennessee & Summer & Kentucky & Simpson & Warren & -0.6 & 0.6 \\
\hline Tennessee & Summer & Kentucky & Allen & Warren & 2.6 & 3.2 \\
\hline Tennessee & Macon & Kentucky & Allen & Barren & 6.7 & 4.0 \\
\hline Tennessee & Macon & Kentucky & Monroe & Barren & 2.9 & -0.4 \\
\hline Tennessee & Clay & Kentucky & Monroe & Metcalfe & 3.4 & 1.9 \\
\hline Tennessee & Clay & Kentucky & Cumberland & Adair & 2.3 & 3.0 \\
\hline Tennessee & Pickett & Kentucky & Clinton & Russell & 1.4 & 2.3 \\
\hline Tennessee & Pickett & Kentucky & Wayne & Pulaski & 0.3 & 1.5 \\
\hline Tennessee & Scott & Kentucky & McCreary & Pulaski & -1.4 & 0.6 \\
\hline Tennessee & Campbell & Kentucky & Whitley & Laurel & 0.7 & 0.8 \\
\hline Tennessee & Claibome & Kentucky & Bell & Clay & 0.7 & 0.4 \\
\hline Tennessee & Lake & Missouri & New Madrid & Stoddard & 5.4 & 1.4 \\
\hline Tennessee & Dyer & Missouri & Pemiscot & Dunklin & 0.4 & 1.6 \\
\hline Mississippi & DeSoto & Arkansas & Crittenden & Saint Francis & -2.6 & 0.3 \\
\hline Mississippi & Tunica & Arkansas & Lee & Monroe & 4.5 & 1.8 \\
\hline Mississippi & Coahoma & Arkansas & Philips & Arkansas & 1.2 & 1.6 \\
\hline
\end{tabular}




\begin{tabular}{|c|c|c|c|c|c|c|}
\hline Mississippi & Bolivar & Arkansas & Desha & Lincoln & -1.7 & 0.4 \\
\hline Mississippi & Washington & Arkansas & Chicot & Ashley & -1.6 & -1.1 \\
\hline Kansas & Doniphan & Missouri & Holt & Nordaway & -2.1 & -0.3 \\
\hline Kansas & Doniphan & Missouri & Andrew & Gentry & -2.9 & -0.7 \\
\hline Kansas & Doniphan & Missouri & Buchanan & DeKalb & -1.5 & -0.3 \\
\hline Kansas & Atchison & Missouri & Buchanan & Clinton & 0.8 & -0.5 \\
\hline Kansas & Leavenworth & Missouri & Platte & Clinton & 4.7 & 2.2 \\
\hline Kansas & Johnson & Missouri & Jackson & Lafayette & 0.1 & 1.1 \\
\hline Kansas & Miami & Missouri & Cass & Johnson & -1.4 & -1.3 \\
\hline Kansas & Linn & Missouri & Bates & Henry & 0.1 & -0.4 \\
\hline Kansas & Bourbon & Missouri & Vemon & Cedar & -3.3 & -4.4 \\
\hline Kansas & Crawford & Missouri & Barton & Dade & 4.6 & 3.5 \\
\hline Kansas & Cherokee & Missouri & Jasper & Lawrence & 1.9 & 0.1 \\
\hline Michigan & Gogebic & Wisconsin & Iron & Ashland & 2.5 & 1.2 \\
\hline Michigan & Gogebic & Wisconsin & Vilas & Oneida & 3.0 & 2.0 \\
\hline Michigan & Iron & Wisconsin & Forest & Langlade & 0.9 & 0.5 \\
\hline Michigan & Dickinson & Wisconsin & Marinette & Oconto & 4.7 & 3.5 \\
\hline Michigan & Menominee & Wisconsin & Marinette & Oconto & 2.4 & 2.5 \\
\hline North Dakota & Pembina & Minnesota & Kittson & Roseau & 0.5 & 2.2 \\
\hline North Dakota & Walsh & Minnesota & Marshall & Beltrarni & -3.5 & -1.4 \\
\hline North Dakota & Grand Forks & Minnesota & Polk & Clearwater & 2.6 & 1.9 \\
\hline North Dakota & Traill & Minnesota & Norman & Mahnomen & -0.1 & -1.1 \\
\hline North Dakota & Cass & Minnesota & Clay & Becker & 1.2 & 1.4 \\
\hline North Dakota & Richland & Minnesota & Wilkin & Otter Tail & 1.4 & 0.7 \\
\hline West Virginia & Wayne & Kentucky & Boyd & Carter & 0.3 & 0.6 \\
\hline West Virginia & Wayne & Kentucky & Lawrence & Elliott & 1.9 & 1.0 \\
\hline West Virginia & Mingo & Kentucky & Martin & Johnson & 1.0 & 1.1 \\
\hline West Virginia & MIngo & Kentucky & Pike & Floyd & 0.3 & 0.4 \\
\hline Illinois & Jo Daviess & Iowa & Dubuque & Delaware & -0.8 & 0.6 \\
\hline Illinois & Jo Daviess & Iowa & Jackson & Jones & -1.3 & 0.8 \\
\hline Illinois & Carroll & Iowa & Jackson & Jones & -1.7 & 0.9 \\
\hline Illinois & Whiteside & Iowa & Clinton & Cedar & 0.1 & -0.7 \\
\hline Illinois & Rock Island & Iowa & Scott & Cedar & -0.4 & -0.3 \\
\hline Illinois & Rock Island & Iowa & Muscatine & Johnson & -0.3 & -0.4 \\
\hline Illinois & Mercer & Iowa & Louisa & Washington & 1.3 & 0.4 \\
\hline Illinois & Henderson & Iowa & Des Moines & Henry & 2.4 & 1.5 \\
\hline Illinois & Hancock & Iowa & Lee & Henry & 1.4 & 1.5 \\
\hline Louisiana & Caddo & Arkansas & Miller & Hempstead & 0.3 & 0.9 \\
\hline Louisiana & Bossier & Arkansas & Lafayette & Hempstead & -1.6 & 1.9 \\
\hline Louisiana & Webster & Arkansas & Columbia & Neveda & 0.3 & -0.2 \\
\hline Louisiana & Claiborne & Arkansas & Columbia & Ouachita & 1.0 & 0.8 \\
\hline Louisiana & Union & Arkansas & Union & Calhoun & 2.7 & 1.8 \\
\hline Louisiana & Morehouse & Arkansas & Ashley & Drew & -0.7 & 0.9 \\
\hline Louisiana & West Carroll & Arkansas & Chicot & Drew & 1.3 & 1.9 \\
\hline Louisiana & East Carroll & Arkansas & Chicot & Drew & 2.3 & 1.2 \\
\hline Oklahoma & Delaware & Arkansas & Benton & Madison & 2.0 & 1.8 \\
\hline Oklahoma & Adair & Arkansas & Washington & Madison & 2.1 & 2.1 \\
\hline Oklahoma & Sequoyah & Arkansas & Crawford & Franklin & -0.3 & 0.3 \\
\hline Oklahoma & Le Flore & Arkansas & Sebastian & Logan & 2.5 & 2.0 \\
\hline Oklahoma & Le Flore & Arkansas & Scott & Yell & 0.9 & 0.3 \\
\hline
\end{tabular}




\begin{tabular}{|c|c|c|c|c|c|c|}
\hline Oklahoma & McCurtain & Arkansas & Polk & Montgomery & 2.9 & 2.4 \\
\hline Oklahoma & McCurtain & Arkansas & Sevier & Howard & 0.7 & 2.5 \\
\hline Oklahoma & McCurtain & Arkansas & Littler River & Hempstead & 1.3 & 1.8 \\
\hline Texas & Bowie & Arkansas & Littler River & Howard & -0.6 & -1.6 \\
\hline Texas & Cass & Arkansas & Miller & Hempstead & -1.2 & -0.5 \\
\hline Missouri & McDonald & Arkansas & Benton & Madison & 3.0 & 1.1 \\
\hline Missouri & Barry & Arkansas & Carroll & Madison & 2.0 & -0.4 \\
\hline Missouri & Stone & Arkansas & Carroll & Newton & 1.2 & 0.6 \\
\hline Missouri & Taney & Arkansas & Boone & Newton & 4.4 & 3.9 \\
\hline Missouri & Ozark & Arkansas & Marion & Searcy & 0.7 & -0.7 \\
\hline Missouri & Ozark & Arkansas & Baxter & Stone & 0.9 & -0.2 \\
\hline Missouri & Howell & Arkansas & Fulton & Izard & -0.1 & 0.1 \\
\hline Missouri & Oregon & Arkansas & Sharp & Independence & 0.8 & 0.1 \\
\hline Missouri & Oregon & Arkansas & Randolph & Lawrence & 0.0 & -0.7 \\
\hline Missouri & Ripley & Arkansas & Randolph & Lawrence & 1.3 & 1.3 \\
\hline Missouri & Ripley & Arkansas & Clay & & 0.6 & 0.3 \\
\hline Missouri & Butler & Arkansas & Clay & & 1.1 & 0.6 \\
\hline Missouri & Dunklin & Arkansas & Clay & & 1.1 & 1.0 \\
\hline Missouri & Dunklin & Arkansas & Greene & Lawrence & 0.7 & 1.4 \\
\hline Missouri & Dunklin & Arkansas & Mississippi & Poinsett & 2.8 & 2.1 \\
\hline Missouri & Pemiscot & Arkansas & Mississippi & Poinsett & 2.5 & 0.9 \\
\hline Missouri & Atchison & Iowa & Fremont & & -3.2 & 3.4 \\
\hline Missouri & Nodaway & Iowa & Page & Montgomery & -0.9 & -0.4 \\
\hline Missouri & Worth & Iowa & Taylor & Adams & -4.8 & 0.0 \\
\hline Missouri & Worth & Iowa & Ringgold & Union & -4.1 & 0.2 \\
\hline Missouri & Harrison & Iowa & Ringgold & Union & -1.2 & 0.0 \\
\hline Missouri & Harrison & Iowa & Decatur & Clarke & 1.4 & 0.9 \\
\hline Missouri & Mercer & Iowa & Wayne & Lucas & 9.5 & 10.1 \\
\hline Missouri & Putnam & Iowa & Wayne & Lucas & -1.1 & 0.2 \\
\hline Missouri & Putnam & Iowa & Appanoose & Monroe & -2.2 & -0.3 \\
\hline Missouri & Schuyler & Iowa & Davis & Wapello & 1.1 & -0.2 \\
\hline Missouri & Scotland & Iowa & Van Buren & Jefferson & 1.8 & 1.9 \\
\hline Missouri & Clark & Iowa & Lee & Henry & 3.6 & 3.0 \\
\hline Wisconsin & Vernon & Iowa & Allamakee & Winneshiek & 2.4 & -0.8 \\
\hline Wisconsin & Crawford & Iowa & Allamakee & Winneshiek & 2.7 & 0.7 \\
\hline Wisconsin & Grant & Iowa & Clayton & Fayette & 4.2 & 0.2 \\
\hline Wisconsin & Grant & Iowa & Dubuque & Delaware & 0.2 & -1.0 \\
\hline Wisconsin & Douglas & Minnesota & Carlton & Aitkin & 0.1 & -0.8 \\
\hline Wisconsin & Burnett & Minnesota & Pine & Kanabec & 0.3 & -1.2 \\
\hline Wisconsin & Polk & Minnesota & Chisago & Isanti & 0.6 & 0.1 \\
\hline Wisconsin & St. Croix & Minnesota & Washington & Ramsey & 0.4 & -0.5 \\
\hline Wisconsin & Pierce & Minnesota & Goodhue & Rice & 1.1 & -0.5 \\
\hline Wisconsin & Pepine & Minnesota & Wabasha & Olmsted & 2.3 & 0.9 \\
\hline Wisconsin & Buffalo & Minnesota & Wabasha & Olmsted & 2.4 & 1.2 \\
\hline Wisconsin & Buffalo & Minnesota & Winona & Olmsted & 2.0 & 1.0 \\
\hline Wisconsin & Trempealeau & Minnesota & Winona & Olmsted & 0.6 & -0.2 \\
\hline Wisconsin & La Crosse & Minnesota & Winnoa & Olmsted & 0.5 & -0.2 \\
\hline Wisconsin & La Crosse & Minnesota & Houston & Filmore & 1.5 & 0.2 \\
\hline Wisconsin & Vernon & Minnesota & Houston & Filmore & 1.5 & -1.3 \\
\hline
\end{tabular}




\section{European Central Bank Working Paper Series}

For a complete list of Working Papers published by the ECB, please visit the ECB's website (http://www.ecb.int)

745 "Market discipline, financial integration and fiscal rules: what drives spreads in the euro area government bond market?" by S. Manganelli and G.Wolswijk, April 2007.

746 "U.S. evolving macroeconomic dynamics: a structural investigation" by L. Benati and H. Mumtaz,April 2007.

747 "Tax reform and labour-market performance in the euro area: a simulation-based analysis using the New Area-Wide Model" by G. Coenen, P. McAdam and R. Straub,April 2007.

748 "Financial dollarization: the role of banks and interest rates" by H. S. Basso, O. Calvo-Gonzalez and M. Jurgilas, May 2007.

749 "Excess money growth and inflation dynamics" by B. Roffia and A. Zaghini, May 2007.

750 "Long run macroeconomic relations in the global economy" by S. Dees, S. Holly, M. H. Pesaran and L.V. Smith, May 2007.

751 "A look into the factor model black box: publication lags and the role of hard and soft data in forecasting GDP” by M. Bańbura and G. Rünstler, May 2007.

752 "Econometric analyses with backdated data: unified Germany and the euro area" by E.Angelini and M. Marcellino, May 2007.

753 “Trade credit defaults and liquidity provision by firms" by F. Boissay and R. Gropp, May 2007.

754 "Euro area inflation persistence in an estimated nonlinear DSGE model" by G.Amisano and O.Tristani, May 2007.

755 "Durable goods and their effect on household saving ratios in the euro area" by J.Jalava and I. K. Kavonius, May 2007.

756 "Maintaining low inflation: money, interest rates, and policy stance" by S. Reynard, May 2007.

757 "The cyclicality of consumption, wages and employment of the public sector in the euro area" by A. Lamo, J.J. Pérez and L. Schuknecht, May 2007.

758 "Red tape and delayed entry" by A. Ciccone and E. Papaioannou, June 2007.

759 "Linear-quadratic approximation, external habit and targeting rules" by P. Levine, J. Pearlman and R. Pierse, June 2007.

760 "Modelling intra- and extra-area trade substitution and exchange rate pass-through in the euro area" by A. Dieppe and T.Warmedinger, June 2007.

761 "External imbalances and the US current account: how supply-side changes affect an exchange rate adjustment" by P. Engler, M. Fidora and C. Thimann, June 2007.

762 "Patterns of current account adjustment: insights from past experience" by B. Algieri and T. Bracke, June 2007. 
763 "Short- and long-run tax elasticities: the case of the Netherlands" by G.Wolswijk, June 2007.

764 "Robust monetary policy with imperfect knowledge" by A. Orphanides and J. C.Williams, June 2007.

765 “Sequential optimization, front-loaded information, and U.S. consumption” by A.Willman, June 2007.

766 "How and when do markets tip? Lessons from the Battle of the Bund" by E. Cantillon and P.-L.Yin, June 2007.

767 “Explaining monetary policy in press conferences” by M. Ehrmann and M. Fratzscher, June 2007.

768 "A new approach to measuring competition in the loan markets of the euro area" by M. van Leuvensteijn, J.A. Bikker,A. van Rixtel and C. Kok Sørensen, June 2007.

769 “The ‘Great Moderation' in the United Kingdom” by L. Benati, June 2007.

770 "Welfare implications of Calvo vs. Rotemberg pricing assumptions” by G. Lombardo and D. Vestin, June 2007.

77I "Policy rate decisions and unbiased parameter estimation in typical monetary policy rules" by J. Podpiera, June 2007.

772 "Can adjustment costs explain the variability and counter-cyclicality of the labour share at the firm and aggregate level?" by P. Vermeulen, June 2007.

773 "Exchange rate volatility and growth in small open economies at the EMU periphery" by G. Schnabl, July 2007.

774 "Shocks, structures or monetary policies? The euro area and US after 200 I" by L. Christiano, R. Motto and M. Rostagno, July 2007.

775 "The dynamic behaviour of budget components and output" by A. Afonso and P. Claeys, July 2007.

776 “Insights gained from conversations with labor market decision makers” by T. F. Bewley, July 2007.

777 "Downward nominal wage rigidity in the OECD" by S. Holden and F.Wulfsberg, July 2007.

778 “Employment protection legislation and wages” by M. Leonardi and G. Pica, July 2007.

779 “On-the-job search and the cyclical dynamics of the labor market” by M. U. Krause and T.A. Lubik, July 2007.

780 "Dynamics and monetary policy in a fair wage model of the business cycle" by D. de la Croix, G. de Walque and R.Wouters, July 2007.

781 "Wage inequality in Spain: recent developments” by M. Izquierdo and A. Lacuesta, July 2007.

782 "Panel data estimates of the production function and product and labor market imperfections" by S. Dobbelaere and J. Mairesse, July 2007.

783 "The cyclicality of effective wages within employer-employee matches: evidence from German panel data" by S.Anger, July 2007.

784 "Understanding the dynamics of labor shares and inflation" by M. Lawless and K. Whelan, July 2007

785 “Aggregating Phillips curves” by J. Imbs, E. Jondeau and F. Pelgrin, July 2007. 
786 "The economic impact of merger control: what is special about banking?" by E. Carletti, P. Hartmann and S. Ongena, July 2007.

787 "Finance and growth: a macroeconomic assessment of the evidence from a European angle" by E. Papaioannou, July 2007.

788 "Evaluating the real effect of bank branching deregulation: comparing contiguous counties across U.S. state borders" by R. R. Huang, July 2007. 


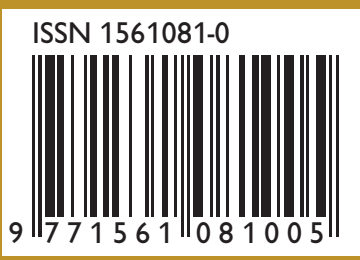




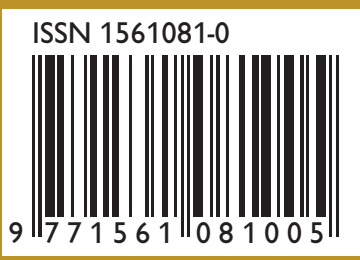

